\title{
Evaporation of a Bicomponent Droplet during Depressurization
}

\author{
Lu Liu ${ }^{a^{*}}$, Yan Liu ${ }^{a}$, Menglong Mi ${ }^{a}$, Zhi Wang ${ }^{\mathrm{a}}$, Lulin Jiang ${ }^{\mathrm{b}}$ \\ a: School of Power, Energy and Mechanical Engineering, North China Electric Power University, 071003, \\ Baoding, China \\ b: Department of Mechanical Engineering, University of Louisiana at Lafayette, Lafayette, LA 70508, USA \\ "Corresponding author Email address: tong1027@gmail.com
}

\begin{abstract}
This paper reports an experimental and numerical study of evaporation process of a two-volatile bicomponent (ethanol/water and acetic acid/water) droplet during depressurization. The environmental pressure, the ambient temperature, and the droplet temperature are investigated during the experiments. A mathematic model is then constructed to simulate the droplet evaporation process. The model solves one-dimensional heat conduction equation and species diffusion equation to acquire the temperature distribution and the concentration distribution inside the droplet. The activity coefficient is introduced to imitate the vapor partial pressure at the droplet surface. By numerical calculations, the variations of temperature distribution and concentration distribution within the ethanol/water droplet and the acetic acid/water droplet are discussed. The effects of composition, final ambient pressure and initial droplet diameter on droplet evaporation are also analyzed in the current study. Results show that the model predictions agree well with the measured temperature data, demonstrating the soundness of the present model and providing insight into the complex heat and mass transfer during the evaporation process of a bicomponent droplet under depressurization.
\end{abstract}

Keywords: evaporation; species diffusion; depressurization; bicomponent

\section{Introduction}

Droplet evaporation during depressurization is a coupled heat and mass transfer process accompanied with phase change, which has been widely used in spray drying, flash distillation, and desalination. Many studies have so far investigated water droplet evaporation under reduced pressure. For experimental studies, Owen and Jalil [1] recorded the transient pressure and the droplet temperature during flash evaporation through the droplet hanging method. Satoh et al. [2], 
Liu et al. [3] and Du et al. [4] experimentally investigated the shape change and the temperature variation of a water droplet during rapid evaporation. While for theoretical studies, Shin et al. [5] and Kim et al. [6] analyzed the heat and mass transfer process of a water droplet during rapid evaporation by using diffusion control model. Zhang et al. [7] established a lumped thermodynamic model to predict the droplet temperature variation during flash evaporation and freezing process. Cheng et al. [8] developed a comprehensive mathematical model of vacuum flash evaporation cooling of a water droplet based on the film controlled evaporation model and numerical analysis of the droplet temperature and diameter after evaporation. Besides, Aguilar et al. [9] and Zhou et al. [10] experimentally investigated the formation and the dynamic characteristics of spray flash evaporation. The mean size and the temperature of spray droplets were experimentally obtained and numerically predicted.

Although rapid evaporation process of a water droplet during depressurization has received considerable attention, few studies have been research on the evaporation process of a bicomponent droplet during depressurization. Luo et al. [11] experimentally investigated the factors influencing the temperature variation of a brine droplet under reduced pressure. Those parameters involve initial salt concentration, final ambient pressure, initial droplet temperature and initial droplet diameter. Zhang et al. $[12,13]$ studied the steam carrying effect in static flash of both pure water and aqueous $\mathrm{NaCl}$ solution. Muthunayagam et al. [14] developed a vapor diffusion model to estimate the variations of droplet temperature and diameter during evaporation process of a saline water droplet at low temperatures and reduced pressures. Liu et al. [15] constructed a mathematical model to simulate the evaporation process of a saline droplet during depressurization. The influencing factors on saline droplet temperature were theoretically analyzed. Nešić et al. [16] presented a more detailed description of various stages of droplet evaporation and drying. Their investigation was mainly focused on solid layer formation of a droplet containing colloidal mater. Gopireddy et al. [17] numerically studied the evaporation and drying process of a droplet of polymer in water and mannitol in water. The effects of drying conditions such as gas velocity, temperature, and relative humidity on evaporation and drying rate were analyzed. In all the previous work, only water evaporates within the droplets.

However, the evaporation process of a two-volatile component (such as: water/ethanol) droplet, also called bicomponent droplet, is more complex. The variation of species concentration during evaporation further increases the complexity of the problem. Sazhin et al. [18, 19] experimentally and theoretically studied heating and evaporation process of a bicomponent droplet at atmospheric pressure. The model considered the distribution of temperature and diffusion of liquid species inside the droplet, the effect of recirculation in the moving droplets on heat and mass diffusion, and the effect of the non-unity activity coefficient. The time evolutions of droplet 
temperature were discussed by comparing numerical results with experimental data. Maqua et al. [20] experimentally measured temperature variation of a bicomponent droplet in hot air plume by applying the three color laser induced fluorescence technique. The influences of initial composition and droplet diameter were revealed. Yarin et al. [21] theoretically and experimentally investigated the evaporation of acoustically levitated droplets of binary liquid mixtures. The temporal evolutions of the droplets surface and the aspect ratio of the droplet contour were explored. Raghuram et al. [22] numerical studied the evaporation of stationary, spherical, two-component liquid droplets exposed to forced convective hot air at atmosphere pressure. The relative strengths of forced convection and Marangoni convection, the resultant flow, temperature and species fields within the droplet were mainly analyzed. Ebrahimian et al. [23] developed a predictive evaporation model for multi-component hydrocarbon droplets at atmospheric and high pressures to investigate effects of pressure and composition.

Up to now, the investigations on evaporation of a bicomponent droplet have covered the high pressure domain as well as the atmospheric environment, which can be applied to the combustion of liquid fuel. However, the evaporation characteristics of a bicomponent droplet during depressurization remain unknown. Also, the temperature and concentration distributions inside the droplet have not been investigated in detail. The present paper aims to explore evaporation process of a bicomponent droplet during depressurization, with the two components evaporating simultaneously. An experimental work has been performed to measure the environmental pressure, the ambient temperature and the droplet temperature during depressurization. A mathematical model is developed to simulate the droplet temperature variation with the gradual decrease in ambient pressure. The proposed model also simulates the heat and mass transfers because of evaporation and convection at the droplet surface, accompanying the species diffusion and the temperature gradient inside the droplet. The activity coefficient is introduced to simulate the vapor partial pressure at the droplet surface. The effects of droplet components and final environmental pressure on droplet evaporation are theoretically analyzed for ethanol/water droplets and acetic acid/water droplets. The model calculations help to comprehensively understand the heat and mass transfer process of evaporation of a bicomponent droplet during depressurization.

\section{$2 \quad$ Experimental System}

The schematic drawing of the experimental apparatus is shown in Figure 1. It consists of four subsystems including a test vessel, a vacuum system, a photography system and a data acquisition system. The test vessel is mainly made from stainless steel, with two transparent windows on both sides. The test vessel is coated with a heating layer and an insulating layer to adjust the ambient 
temperature and the initial temperature of the droplet. The vacuum system contains a vacuum pump and a vacuum chamber with 800 times larger volume than that of the test vessel. The chamber is connected to the test vessel through a tube of $25 \mathrm{~mm}$ in diameter. An electro-magnetic valve is installed between the tube and the test vessel. The photographic system for droplet imaging includes a high-speed camera (Optronis CamRecord 450, Germany) which can take the maximum 2000 frames per second (fps) at 400 pixels by 300 pixels. A data acquisition system (National Instrument, USA) collects the data from the thermocouples, and the pressure transducer.

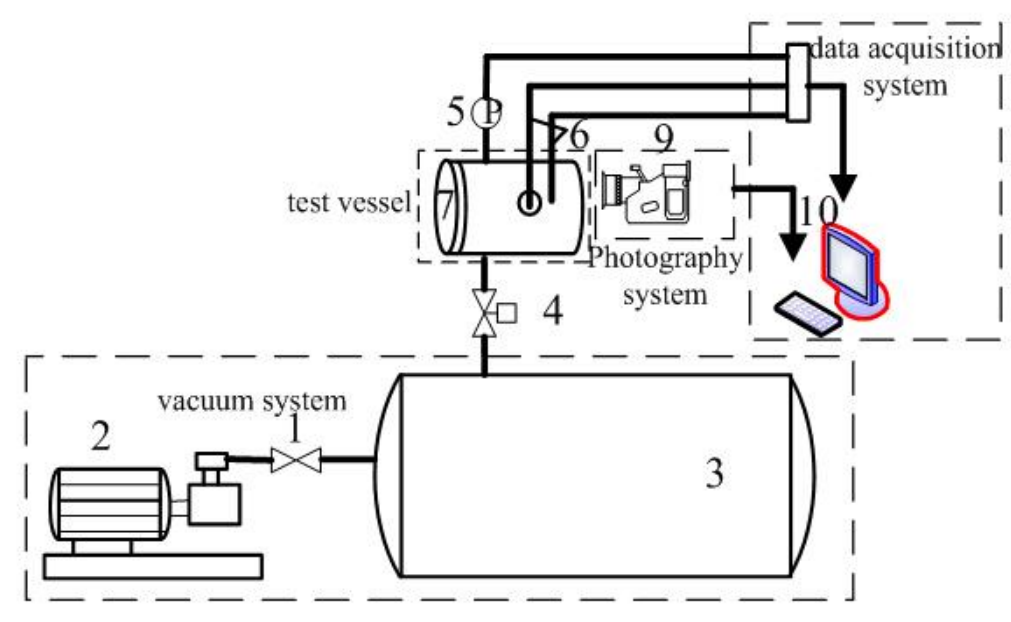

Figure 1: Schematic diagram of the experimental system

( 1 ball valve, 2 vacuum pump, 3 vacuum chamber, 4 electro-magnetic valve, 5 pressure transducer, 6 thermocouple, 7 test vessel, 8 NI data acquisition system, 9 high-speed camera, 10 computer)

During the experiment, a droplet, about $2 \mathrm{~mm}$ in diameter, was suspended in the test vessel on a thin wire (200 $\mu \mathrm{m}$ in diameter) thermocouple joint. The other thermocouple was used to measure the ambient temperature. The liquid was delivered through a syringe with a long needle. The droplet was formed by slowly pushing the syringe after the system was sealed. Before experiments, the centre of the droplet was placed near the thermocouple junction in order to reduce the influence of the thermocouple on the shape and the evaporation process of the droplet during depressurization. After the droplet was steadily hanging, the air in the test vessel was evacuated quickly by opening the electro-magnetic valve connecting to the vacuum chamber, resulting in the thermocouple position close to the droplet surface due to the strong airflow and the surface tension of the droplet. Meanwhile, the data acquisition system started collecting the data from the thermocouples and the pressure transducer. The absolute error of the thermocouple measurement is $\pm 0.2^{\circ} \mathrm{C}$. An absolute pressure transducer (Rosement 3051CA, USA) was utilized to measure the ambient pressure in test vessel, and the measurement precision is $0.065 \%$ of span. 
In this section, a mathematical model is developed to estimate the temperature transition and the concentration variation of a bicomponent droplet during depressurized evaporation. The model is based on the energy conservation and the species diffusion in liquid phase. The variation of physical properties with temperature is also considered. The model assumptions are as follows: (1) the droplet is a perfect sphere, only the temperature distribution and the concentration distribution in radial direction are considered; (2) the heat and mass transfer in gas phase is considered as quasisteady; (3) thermal radiation between the droplet surface and the surrounding is negligible.

\subsection{Energy Conservation in the Liquid Phase}

Assuming that the processes inside the droplet are spherically symmetric, the energy conservation in the liquid phase can be written as follows:

$$
\rho_{l} c_{p l} \frac{\partial T}{\partial t}=\frac{1}{r^{2}} \frac{\partial}{\partial r}\left(\lambda_{\mathrm{eff}} r^{2} \frac{\partial T}{\partial r}\right)
$$

where $T$ is the liquid temperature, $\rho_{l}$ and $c_{p l}$ are the density and the specific heat capacity of liquid respectively, $r$ is the radial coordinate, and $t$ stands for time. The physical properties of the binary solution are calculated as $[18,24]$ :

$$
\begin{gathered}
\rho_{l}=\left(\frac{Y_{l 1}}{\rho_{l 1}}+\frac{Y_{l 2}}{\rho_{l 2}}\right)^{-1} \\
c_{p l}=Y_{l 1} c_{p l 1}+Y_{l 2} c_{p l 2} \\
\ln \mu_{l}=X_{l 1} \ln \mu_{l 1}+X_{l 2} \ln \mu_{l 2} \\
\lambda_{l}=Y_{l 1} \lambda_{l 1}+Y_{l 2} \lambda_{l 2}-0.72 Y_{l 1} Y_{l 2}\left|\lambda_{l 2}-\lambda_{l 1}\right|
\end{gathered}
$$

where for binary $i=1$ and $2, Y_{l i}$ and $X_{l i}$ are the mass fraction and the molar fraction of the $i$ th component in liquid phase, respectively.

$\lambda_{\text {eff }}$ is the so-called effective thermal conductivity, which is related to the air flow around the droplet.

$$
\lambda_{\text {eff }}=\chi \lambda_{l}
$$

where the coefficient $\chi$ varies from 1 to 2.72 and can be approximated as $[18,19,25]$ :

$$
\chi=1.86+0.86 \tanh \left[2.225 \log _{10}\left(P e_{l} / 30\right)\right]
$$

The model based on Equations (6) and (7) is known as the effective thermal conductivity model, which considers the internal circulation flow enhancing heat transfer inside the droplet. Liquid transport properties were used for calculating Peclet number $P e_{l}$ : 


$$
P e_{l}=\operatorname{Re}_{l} \operatorname{Pr}_{l}=\frac{2 \rho_{l} u_{\mathrm{s}} r_{\mathrm{s}}}{\mu_{l}} \operatorname{Pr}_{l}
$$

where $r_{\mathrm{s}}$ is the droplet radius, $u_{\mathrm{s}}$ is the maximal liquid velocity at the droplet surface and can be estimated by the following relation $[25,26]$ :

$$
u_{\mathrm{s}}=\frac{12.69}{32} u_{\mathrm{a}} \frac{\bar{\mu}}{\mu_{l}} \frac{R e_{\mathrm{a}}}{R e_{\mathrm{a}}^{2 / 3}}
$$

$u_{\mathrm{a}}$ is the air velocity around the droplet, $R e_{\mathrm{a}}\left(=2 \bar{\rho} u_{\mathrm{a}} r_{\mathrm{s}} / \bar{\mu}\right)$ denotes the Reynolds number of air movement, $\bar{\mu}$ signifies the average dynamic viscosity of vapor-air mixture.

The initial condition is:

$$
t=0, \quad r_{\mathrm{s}}=r_{\mathrm{s} 0}, \quad T=T_{0}
$$

and the boundary conditions are:

$$
\begin{gathered}
r=0, \quad \frac{\partial T}{\partial r}=0 \\
r=r_{\mathrm{s}}(t), \quad-\lambda_{\text {eff }} \frac{\partial T}{\partial r}=q_{\mathrm{m}}+q_{\mathrm{h}}
\end{gathered}
$$

where $q_{\mathrm{m}}$ and $q_{\mathrm{h}}$ are the heat fluxes because of evaporation and convection at the droplet surface, separately.

\subsection{Species Diffusion in the Liquid Phase}

The equations for mass fractions of liquid species can be presented in the following form:

$$
\frac{\partial Y_{l i}}{\partial t}=\frac{1}{r^{2}} \frac{\partial}{\partial r}\left(D_{\text {eff }} r^{2} \frac{\partial Y_{l i}}{\partial r}\right)
$$

where $i=1,2 ; D_{\text {eff }}$ is the effective mass diffusivity in liquid phase, which can be calculated as:

$$
D_{\text {eff }}=\chi_{\mathrm{D}} D_{l}
$$

where $D_{l}$ is the liquid mass diffusivity, as for the binary system, the calculation method can be simplified to [18]:

$$
\begin{gathered}
D_{l}=X_{l 1} D_{12}^{0}+X_{l 2} D_{21}^{0} \\
D_{A B}^{0}=\frac{7.4 \times 10^{-12} \sqrt{\varphi M_{B}} T}{\mu_{B} V_{A}^{0.6}}
\end{gathered}
$$

Where $D_{A B}^{0}$ is the diffusion coefficient of solute $A$ in solvent $B, \mathrm{~m}^{2} / \mathrm{s}, M_{\mathrm{B}}$ is the molar mass of solvent $B, \mathrm{~kg} / \mathrm{kmol}, \mu_{B}$ is the dynamic viscosity of solvent $B, \mathrm{cp}\left(1 \mathrm{cp}=10^{-3} \mathrm{~kg} \mathrm{~m}^{-1} \mathrm{~s}^{-1}\right), V_{A}$ is the molar volume of solute $A$ at its normal boiling temperature, $\mathrm{cm}^{3} / \mathrm{mol}, \varphi$ is the associated factor of solvent $B$ ( $\varphi=1.5$ if $B$ is ethanol, $\varphi=2.6$ if $B$ is water, $\varphi=1$ if $B$ is acetic acid). 
Similar to Equation (7), the coefficient $\chi_{D}$ considers the internal circulation flow enhancing mass transfer inside the droplet, and it can be estimated as follows [18, 19].

$$
\chi_{D}=1.86+0.86 \tanh \left[2.225 \log _{10}\left(R e_{l} S c_{l} / 30\right)\right]
$$

where $S c_{l}$ is the liquid Schmidt number defined as:

$$
S c_{l}=\frac{\mu_{l}}{\rho_{l} D_{l}}
$$

The initial condition is:

$$
t=0, \quad Y_{l i}=Y_{l i 0}
$$

and the boundary conditions are:

$$
\begin{gathered}
r=0, \quad \frac{\partial Y_{l i}}{\partial r}=0 \\
r=r_{\mathrm{s}}(t), \quad-\rho_{l} D_{\text {eff }} \frac{\partial Y_{l i}}{\partial r}=\frac{\dot{m}}{4 \pi r_{\mathrm{s}}^{2}}\left(\varepsilon_{i}-Y_{l i \mathrm{~s}}\right)
\end{gathered}
$$

where $Y_{l i s}$ is the liquid mass fraction at the droplet surface of the $i$ th component; $\dot{m}$ is the droplet evaporation rate, the calculation of which will be discussed in the next section; $\varepsilon_{i}$ is the fraction of $i$ th species evaporation rate $\left(\dot{m}_{i}=\varepsilon_{i} \dot{m}\right)$, and the value of $\varepsilon_{i}$ can be found from the following relation (in this paper, due to the ambient pressure is very low, the species concentrations in the ambient air can not be ignored) $[18,19,20]$ :

$$
\varepsilon_{i}=\frac{Y_{v i s}-Y_{v i a}}{\sum_{i}\left(Y_{v i s}-Y_{v i a}\right)}
$$

where $Y_{v i s}$ and $Y_{v i a}$ are the vapor mass fraction of the $i$ th component at the droplet surface and in ambient air, respectively.

\subsection{Droplet Evaportion}

The challenge of modelling bicomponent droplet evaporation is mainly attributed to the facts that (1) different species diffuse at different rates, and (2) the evaporation rate of one of the species is affected by the evaporation of other species. The analysis of evaporation of a bicomponent droplet led to the following expression for $\dot{m}[18,19]$ :

$$
\dot{m}=2 \pi \bar{\rho} r_{s} D_{v} S h^{*} \ln \left(1+B_{\mathrm{M}}\right)
$$

where $\bar{\rho}$ is the average density of vapor-air mixture (see in section 3.6); $D_{v}$ is the gas diffusivity for mixed vapor, as for diffusion of single component vapor in air, the value of $D_{v}$ is estimated from the Wilke and Lee formula [18, 24]:

$$
D_{v}=\frac{\left[3.03-\left(0.98 / M_{v a}^{1 / 2}\right)\right]\left(10^{-2}\right) T^{3 / 2}}{P_{\mathrm{a}} M_{v a}^{1 / 2} \sigma_{v a}^{2} \Omega_{D}}
$$




$$
\begin{gathered}
M_{v a}=2\left[\left(1 / M_{v}\right)+\left(1 / M_{a}\right)\right]^{-1} \\
\sigma_{v a}=\left(\sigma_{v}+\sigma_{a}\right) / 2
\end{gathered}
$$

In the above equations, $P_{\mathrm{a}}$ is ambient pressure in $\mathrm{Pa} ; M_{v}$ and $M_{a}$ are molar masses of vapor and air, respectively; $\sigma_{v}$ and $\sigma_{a}$ are characteristic Lennard-Jones lengths for vapor and air, measured in Angstrom (A). $\Omega_{D}$ is the function of the normalised temperature, given by:

$$
\Omega_{D}=\frac{1.06036}{\left(T^{*}\right)^{0.1561}}+\frac{0.193}{\exp \left(0.47635 T^{*}\right)}+\frac{1.03587}{\exp \left(1.52996 T^{*}\right)}+\frac{1.76474}{\exp \left(3.89411 T^{*}\right)}
$$

with $T^{*}=k_{B} T / \varepsilon_{v a}, \varepsilon_{v a}=\sqrt{\varepsilon_{v} \varepsilon_{a}} \cdot \varepsilon_{v}$ and $\varepsilon_{a}$ are characteristic Lennard-Jones energies for vapor and air, respectively.

In the case of the mixture of vapor components[18, 19], all input parameters (such as $M_{v}, \sigma_{v}, \varepsilon_{v}$ ) are calculated as molar averaged, taking into account their relative molar concentrations $X_{v 1 s} /\left(X_{v 1 s}+X_{v 2 s}\right)$ and $X_{v 2 s} /\left(X_{v 1 s}+X_{v 2 s}\right) . X_{v i s}$ is the vapor molar fraction of the $i$ th species at the droplet surface, and can be computed as follows.

$$
X_{v i s}=\frac{P_{v i s}}{P_{\mathrm{a}}}
$$

Where $P_{v i s}$ is the partial pressure of the $i$ th species at the droplet surface, and its calculation method will be described below.

$S h^{*}$ is the modified Sherwood number that accounts for the effects of convection and Stefan flow, following Abramzon and Sirignano [25], it is given in the following equations:

$$
\begin{gathered}
S h^{*}=2+\frac{(S h-2) B_{\mathrm{M}}}{\left(1+B_{\mathrm{M}}\right)^{0.7} \ln \left(1+B_{\mathrm{M}}\right)} \\
S h=2+0.552 \operatorname{Re}_{\mathrm{a}}{ }^{1 / 2} \overline{S c}^{1 / 3}
\end{gathered}
$$

where $\overline{S c}$ is the average Schmidt number of vapor-air mixture, $\overline{S c}=\bar{\mu} / \bar{\rho} D_{v}$.

In Equation (23), $B_{\mathrm{M}}$ is the Spalding mass transfer number defined as:

$$
B_{M}=\frac{\sum_{i} Y_{v i s}-\sum_{i} Y_{v i a}}{1-\sum_{i} Y_{v i s}}
$$

The value of $Y_{v i s}$ depends on the partial pressure of the $i$ th species in vapor state at the droplet surface $\left(P_{\text {vis }}\right)$ :

$$
\begin{gathered}
Y_{v i s}=\frac{P_{v i s} M_{i}}{\sum_{i}\left(P_{v i s} M_{i}\right)+\left(P_{a}-\sum_{i} P_{v i s}\right) M_{a}} \\
P_{v i s}=X_{l i s} \gamma_{i} P_{v i}^{*}
\end{gathered}
$$

where $X_{\text {lis }}$ is the liquid molar fraction of the $i$ th species at the droplet surface, and it can be estimated as follows: 


$$
X_{l i s}=\frac{Y_{l i s} / M_{i}}{\sum_{i}\left(Y_{l i s} / M_{i}\right)}
$$

where $Y_{l i s}$ is the liquid mass fraction of the $i$ th species at the droplet surface. $p_{v i}^{*}$ is the saturated vapor pressure of the $i$ th species according to the droplet surface temperature, which can be calculated by Clausius-Clapeyron equation. $\gamma_{i}$ is the activity coefficient of the $i$ th species, and it can be described as below for binary system [21]:

$$
\left\{\begin{array}{l}
\gamma_{1}=\frac{1}{X_{l 1 s}+\alpha X_{l 2 s}} \exp \left[-X_{l 2 s}\left(\frac{\beta}{X_{l 2 s}+\beta X_{l 1 s}}-\frac{\alpha}{\alpha X_{l 2 s}+X_{l 1 s}}\right)\right] \\
\gamma_{2}=\frac{1}{X_{l 2 s}+\beta X_{l 1 s}} \exp \left[X_{l 1 s}\left(\frac{\beta}{X_{l 2 s}+\beta X_{l 1 s}}-\frac{\alpha}{\alpha X_{l 2 s}+X_{l 1 s}}\right)\right]
\end{array}\right.
$$

In the case of water-ethanol mixture ( $i=1$ is water, $i=2$ is ethanol), $\alpha=0.956, \beta=0.1108$. And for acetic acid-water mixture ( $i=1$ is water, $i=2$ is acetic acid), $\gamma_{i}$ was suggested by Hansen et al. [27]:

$$
\left\{\begin{aligned}
\log \gamma_{1} & =X_{l 2 s}^{2}\left[\frac{0.202}{X_{l 2 s}^{2}}-0.455 X_{l 2 s}+0.623 X_{l 2 s}^{2}+0.080 X_{l 2 s}^{3}\right. \\
& \left.-\exp \left(-2.50 X_{l 2 s}\right)\left(\frac{0.202}{X_{l 2 s}^{2}}+\frac{0.505}{X_{l 2 s}}-0.505\right)\right] \\
\log \gamma_{2} & =X_{l 1 s}^{2}\left[0.683 X_{l 2 s}^{2}+0.080 X_{l 2 s}^{3}+0.505 \exp \left(-2.50 X_{l 2 s}\right)\right]
\end{aligned}\right.
$$

In Equation (31), $Y_{v i a}$ is the vapor mass fraction of the $i$ th component in ambient air, and it is related with the partial pressure of the $i$ th species in ambient air $P_{v i a}$.

$$
Y_{v i a}=\frac{P_{v i a} M_{i}}{\sum_{i}\left(P_{v i a} M_{i}\right)+\left(P_{a}-\sum_{i} P_{v i a}\right) M_{a}}
$$

Assuming the vapor pressure in ambient air is zero before experiment, and then $P_{\text {via }}$ can be calculated by the loss mass of component during evaporation:

$$
P_{v i a}(t)=\int_{0}^{t} \frac{\dot{m}_{i} R_{i} T_{a}}{V} d t
$$

where $R_{i}$ is the gas constant of the $i$ th species, and $V$ is the volume of the test vessel.

\subsection{Heat Fluxes due to Evaproation and Convection}

The heat flux $q_{\mathrm{m}}$ due to evaporation is:

$$
q_{\mathrm{m}}=\frac{\dot{m} L}{4 \pi r_{\mathrm{s}}^{2}}
$$

where $L=\sum_{i} \varepsilon_{i} L_{i}$.

Considering the effect of Stefan flow, Abramzon and Sazhin [28] suggested the heat flux $q_{\mathrm{h}}$ due to convection is: 


$$
q_{h}=\frac{\dot{m} c_{\mathrm{p} v}\left(T_{\mathrm{d}, \mathrm{s}}-T_{\mathrm{a}}\right)}{4 \pi r_{\mathrm{s}}^{2} B_{\mathrm{T}}}
$$

where $c_{\mathrm{p} v}$ is the specific heat capacity of the mixed vapor; $T_{\mathrm{d}, \mathrm{s}}$ and $T_{\mathrm{a}}$ are the temperatures at the droplet surface and in ambient air, respectively. $B_{\mathrm{T}}$ is the Spalding heat transfer number, which can be estimated as follows:

$$
\begin{gathered}
B_{\mathrm{T}}=\left(1+B_{\mathrm{M}}\right)^{\varphi}-1 \\
\varphi=\left(\frac{c_{\mathrm{p} v}}{c_{\mathrm{pa}}}\right)\left(\frac{S h^{*}}{N u^{*}}\right) \frac{1}{L e}
\end{gathered}
$$

where $L e=\bar{\lambda} / \bar{\rho} \bar{c}_{\mathrm{p}} D_{v}$ is the Lewis number, and the modified Nusselt number $\left(\mathrm{Nu}{ }^{*}\right)$ can be calculated as below:

$$
\begin{gathered}
N u^{*}=2+\frac{(N u-2) B_{\mathrm{T}}}{\left(1+B_{\mathrm{T}}\right)^{0.7} \ln \left(1+B_{\mathrm{T}}\right)} \\
N u=2+0.552 \operatorname{Re}_{\mathrm{a}}{ }^{1 / 2} \overline{\operatorname{Pr}}^{1 / 3}
\end{gathered}
$$

$\overline{P r}$ is the average Prandtl number of vapor-air mixture, $\overline{P r}=\bar{\mu} \overline{c_{\mathrm{p}}} / \bar{\lambda}$.

\subsection{Air Flow Velocity $u_{\mathrm{a}}$ around the Droplet}

Revealed in preliminary experiments, strong air movement and droplet swing are induced once the magnetic valve is suddenly opened. In the test vessel, it takes approximate $3 \mathrm{~s}$ to reach the final vacuum pressure, while air flowing continuously out of the vessel and thus leading to a convective effect on droplet evaporation. The Reynolds number of air flow $R e_{\mathrm{a}}$ affects both $N u^{*}$ and $S h^{*}$ characterizing the convection impact (see from the equations 29, 30 and 43, 44).

The air velocity $u_{\mathrm{a}}$ around the droplet can be estimated based on the mass flow rate out of the test vessel. The air is reasonably assumed as an ideal gas for the test case, and hence $u_{\mathrm{a}}$ can be computed in the following formula:

$$
u_{\mathrm{a}}=f \frac{R_{\mathrm{a}} T_{\mathrm{a}}}{P_{\mathrm{a}}} \frac{d m_{\mathrm{a}}}{d t} \frac{1}{A_{\mathrm{C}}}
$$

Where $R_{\mathrm{a}}$ is the gas constant of air, $A_{\mathrm{C}}$ is the cross section area at the location where the droplet is hanging, $f$ is the correction factor from the experiments [15]. The air mass flow rate out of the test vessel can be calculated based on the measured pressure and temperature data in the vessel as follows:

$$
\frac{d m_{\mathrm{a}}}{d t}=\frac{V}{R_{\mathrm{a}} T_{\mathrm{a}}} \frac{d P_{\mathrm{a}}}{d t}-\frac{P_{\mathrm{a}} V}{R_{\mathrm{a}} T_{\mathrm{a}}^{2}} \frac{d T_{\mathrm{a}}}{d t}
$$




\subsection{Gas Average Properties of Vapor-Air Mixture}

The Equations (9),(23), (30), (42), (44) contain the gas average properties for the mixture of vapors of the two components (1 and 2) and air (3), which can be calculated as follows [24]:

$$
\begin{gathered}
\bar{\rho}=\left[\frac{Y_{v 1 r}}{\rho_{v 1}}+\frac{Y_{v 2 r}}{\rho_{v 2}}+\frac{\left.1-Y_{v 1 r}-Y_{v 2 r}\right]^{-1}}{\rho_{a}}\right. \\
\bar{c}_{\mathrm{p}}=Y_{v 1 r} c_{p v 1}+Y_{v 2 r} c_{p v 2}+\left(1-Y_{v 1 r}-Y_{v 2 r}\right) c_{p a} \\
\bar{\mu}=\frac{X_{v 1 r} \mu_{v 1}}{X_{v 1 r}+X_{v 2 r} \phi_{12}+\left(1-X_{v 1 r}-X_{v 2 r}\right) \phi_{13}}+\frac{X_{v 2}}{X_{v 1 r} \phi_{21}+X_{v 2 r}+\left(1-X_{v 1 r}-X_{v 2 r}\right) \phi_{23}} \\
+\frac{\left(1-X_{v 1 r}-X_{v 2 r}\right) \mu_{a}}{X_{v 1 r} \phi_{31}+X_{v 2 r} \phi_{32}+\left(1-X_{v 1 r}-X_{v 2 r}\right)} \\
\bar{\lambda}=\frac{X_{v 1 r} \lambda_{v 1}}{X_{v 1 r}+X_{v 2 r} A_{12}+\left(1-X_{v 1 r}-X_{v 2 r}\right) A_{13}}+\frac{X_{v 22} \lambda_{v 2}}{X_{v 1 r} A_{21}+X_{v 2 r}+\left(1-X_{v 1 r}-X_{v 2 r}\right) A_{23}} \\
+\frac{\left(1-X_{v 1 r}-X_{v 2 r}\right) \lambda_{a}}{X_{v 1 r} A_{31}+X_{v 2 r} A_{32}+\left(1-X_{v 1 r}-X_{v 2 r}\right)}
\end{gathered}
$$

where the reference vapor mass fraction $\left(Y_{v i r}\right)$, the reference vapor molar fraction $\left(X_{v i r}\right)$ and the reference temperature $\left(T_{r}\right)$ are calculated based on the '1/3 rule' [29] as below:

$$
\begin{array}{r}
Y_{v i r}=Y_{v i s}+\left(Y_{v i a}-Y_{v i s}\right) / 3 \\
X_{v i r}=X_{v i s}+\left(X_{v i a}-X_{v i s}\right) / 3 \\
T_{r}=T_{d, s}+\left(T_{a}-T_{d, s}\right) / 3
\end{array}
$$

\subsection{Numerical Solution}

During depressurized evaporation, the droplet radius decreases continuously. A coordinate transformation method is applied to solve such moving boundary problem. The droplet radius $r_{\mathrm{s}}(t)$ is fixed in the computational domain by transforming the original physical coordinate into the computation coordinate through dimensionless factor $\eta$ :

$$
\eta=\frac{r}{r_{\mathrm{s}}(t)} \quad(0 \leq \eta \leq 1)
$$

Then energy Equation (1) and the species diffusion Equation (13) can be transformed to the new coordinate system as follows:

$$
\begin{gathered}
\rho_{l} c_{p l} \frac{\partial T}{\partial t}=\frac{1}{r_{\mathrm{s}}^{2} \eta^{2}} \frac{\partial}{\partial \eta}\left(\lambda_{\mathrm{eff}} \eta^{2} \frac{\partial T}{\partial \eta}\right)+\rho_{l} c_{p l} \frac{\eta}{r_{\mathrm{s}}} \frac{d r_{\mathrm{s}}}{d t} \frac{\partial T}{\partial \eta} \\
\frac{\partial Y_{l i}}{\partial t}=\frac{1}{r_{\mathrm{s}}^{2} \eta^{2}} \frac{\partial}{\partial \eta}\left(D_{\mathrm{eff}} \eta^{2} \frac{\partial Y_{l i}}{\partial \eta}\right)+\frac{\eta}{r_{\mathrm{s}}} \frac{d r_{\mathrm{s}}}{d t} \frac{\partial Y_{l i}}{\partial \eta}
\end{gathered}
$$

The numerical algorithm is given below: 
1. At a given time step, if the $j$ th iteration for the droplet surface temperature is $T_{d, \mathrm{~s}}^{j}$, and the liquid mass fraction of the $i$ th component at the droplet surface is $Y_{l i s}{ }^{j}$, then calculate $X_{l i s}$, and the physical properties of liquid, such as $\rho_{l}, c_{\mathrm{pl}}, S c_{l}, D_{l}$, etc.

2. Calculate $\gamma_{i}$, and thus $p_{v i s}$.

3. Calculate $Y_{v i s}, Y_{v i a}, Y_{v i r}, X_{v i r}, T_{r}$, and the gas average properties of vapor-air mixture, such as $\bar{\rho}, \overline{c_{\mathrm{p}}}, \bar{\mu}, \bar{\lambda}$ etc.

4. Calculate $u_{\mathrm{a}}, u_{\mathrm{s}}$, and thus $R e_{\mathrm{a}}$, as well as $\chi, \lambda_{\text {eff }}, \chi_{\mathrm{D}}, D_{\text {eff. }}$.

5. Calculate $D_{v}$ and $B_{\mathrm{M}}$, and thus $S h, S h^{*}$. Iterative calculate $\varphi$, and thus $B_{\mathrm{T}}, N u, N u^{*}$.

6. Calculate $\dot{m}, \varepsilon_{i}$ and $L$, and then $q_{\mathrm{m}}, q_{\mathrm{h}}$.

7. Solve the species diffusion equation to obtain the concentration distribution inside the droplet, including a new liquid mass fraction at the droplet surface $Y_{l i s}^{j+1}$.

8. Solve the energy equation to obtain the temperature distribution inside the droplet, including a new droplet surface temperature $T_{d, \mathrm{~s}}{ }^{j+1}$.

9. Use the new droplet surface temperature and the new liquid mass fraction, repeat steps (1)-(8) until desired convergences are achieved simultaneously. The convergence criterions are taken as

$$
\left|T_{d, s}{ }^{j+1}-T_{d, s}{ }^{j}\right|<0.001 K \text { and }\left|Y_{l i s}{ }^{j+1}-Y_{l i s}{ }^{j}\right|<0.001
$$

10. Till convergence criterions are satisfied, a new droplet radius is calculated:

$$
r_{\mathrm{s}}(t)=\left(\frac{m_{0}-\int_{0}^{t} \dot{m} d t}{4 \pi \rho_{l} / 3}\right)^{1 / 3}
$$

The solution procedure is then moved to the next time step. A time step of $0.01 \mathrm{~ms}$ is used for the model calculation, and for the finite difference method, 100 nodes along the radius of droplet are required.

\section{$4 \quad$ Results and Discussions}

\subsection{Experimental Data}

Figure 2 presents the measured droplet temperatures and the ambient pressure in the test vessel evolving with time. In Figure 2(a), a 75\% ethanol - 25\% water mixture droplet is used, with the initial droplet diameter of $D_{0}=2 \mathrm{~mm}$, the initial droplet temperature of $T_{0}=5^{\circ} \mathrm{C}$, the initial ambient temperature of $T_{\mathrm{a}, 0}=15^{\circ} \mathrm{C}$, and the ambient pressure varying from 1 atmosphere to $2400 \mathrm{~Pa}$. In Figure 2(b), a 50\% acetic acid $-50 \%$ water mixture droplet is utilized, with $D_{0}=2.2 \mathrm{~mm}, T_{0}=$ $14.5^{\circ} \mathrm{C}, T_{\mathrm{a}, 0}=18^{\circ} \mathrm{C}$, and the ambient pressure changing from 1 atmosphere to $4800 \mathrm{~Pa}$. 


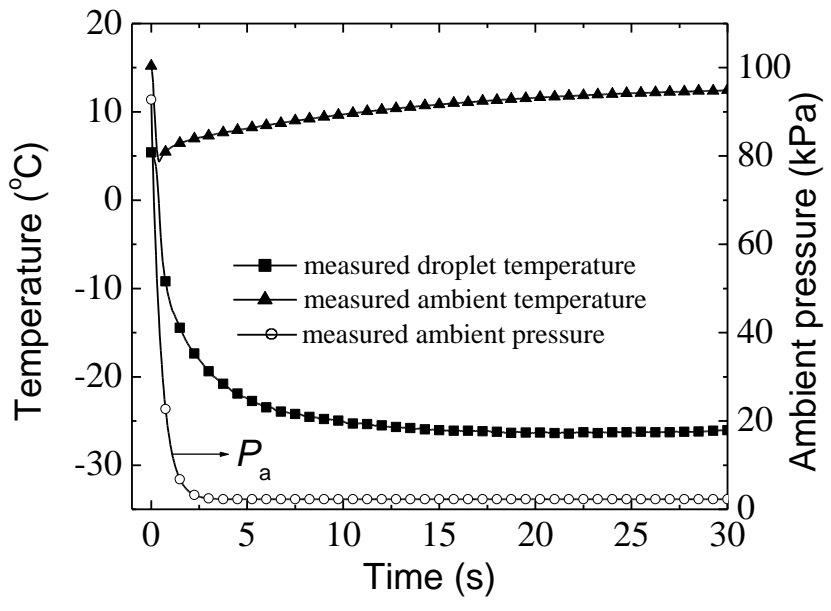

(a)

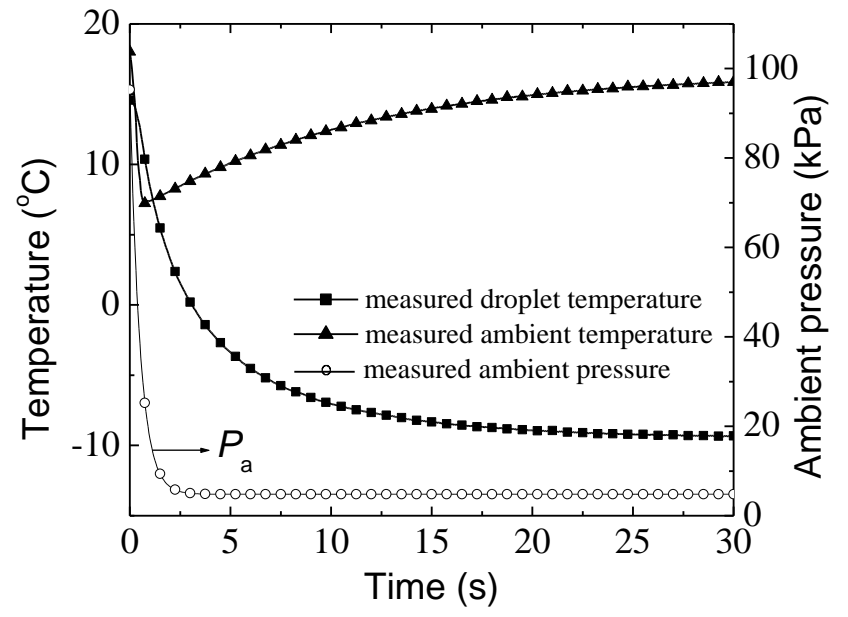

(b)

Figure 2: Temporal variations of the bicomponent droplet temperature, the ambient temperature and the environmental pressure in the test vessel for (a) a 75\% ethanol $-25 \%$ water mixture droplet with $D_{0}=2 \mathrm{~mm}, T_{0}=5^{\circ} \mathrm{C}, T_{\mathrm{a}, 0}=15^{\circ} \mathrm{C}$, and the ambient pressure from 1 atm to $2400 \mathrm{~Pa}$; and (b): a $50 \%$ acetic acid $-50 \%$ water mixture droplet with $D_{0}=2.2 \mathrm{~mm}, T_{0}=14.5^{\circ} \mathrm{C}, T_{\mathrm{a}, 0}=18^{\circ} \mathrm{C}$, and the ambient pressure from 1 atm to $4800 \mathrm{~Pa}$. )

The variation of ambient pressure in the test vessel remains almost the same for most of the experimental conditions, as shown in Figure 2. The pressure change in the test vessel can be divided into two stages: a stage with fast pressure dropping for the first $2.5 \mathrm{~s}$ after the valve is opened and followed by the stage of an almost constant pressure. The first stage can be attributed to the fast movement of the air exiting the test vessel. Such a strong air movement would result in a strong convective evaporation from the droplet surface. Once the pressure reaches a constant value, the air flow in the test vessel stops, the evaporation is therefore presumably resulted from a pure diffusion process. During the fast pressure dropping stage, the ambient temperature in the test vessel decreases about $10^{\circ} \mathrm{C}$ in 1 second. Then, the ambient temperature gradually increases, till $t=15 \mathrm{~s}$, it remains constant. Correspondingly, the measured droplet temperature decreases rapidly during the dramatic pressure drop and then the droplet temperature decreases slowly, till it reaches the minimum value.

Figure 3 illustrates droplet images captured by the high speed camera at 50fps during depressurized evpaoration of a $75 \%$ ethanol $-25 \%$ water droplet, with the ambient pressure in the test vessel dropping from 1 atmosphere to 2400Pa. The droplet swing can be seen when the magentic valve is suddenly opened, then bubble forms and quickly bursts $(t=0.4 \mathrm{~s}, 0.42 \mathrm{~s}$, and $0.58 \mathrm{~s})$ within the droplet during the pressure dropping stage. Note that, bubble formation and burst absorb latent energy from the droplet, accelerating temperature drop of the droplet and hence affecting the evaporation process. Till the pressure maintaince stage, the bubble burst is not vigorous. However, the existence of small bubbles can still be seen in the liquid droplet $(t=4.78 \mathrm{~s})$. After $t=10 \mathrm{~s}$, the 
droplet evaproates stably. Figure 3 also indicates that during depressurized evaporaiton, the thermocouple junction is closer to the droplet surface, because of the effects of surface tension and the air flow.

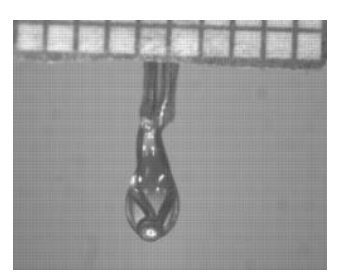

0s

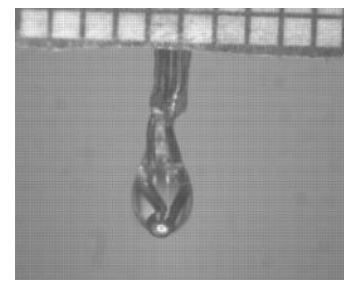

$0.44 \mathrm{~s}$

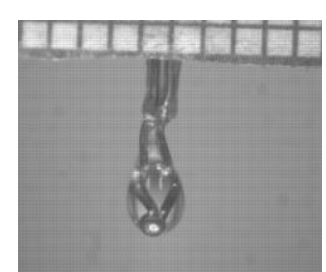

$0.3 \mathrm{~s}$

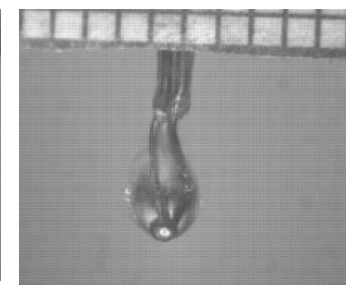

$0.58 \mathrm{~s}$

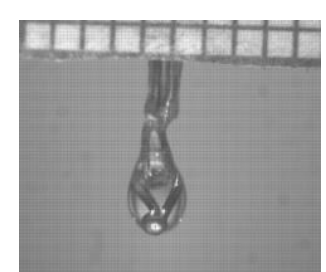

$0.34 \mathrm{~s}$

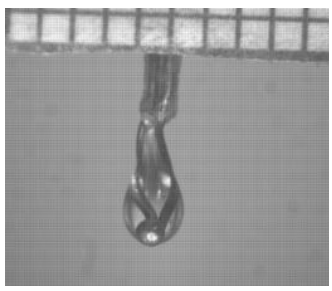

$0.64 \mathrm{~s}$

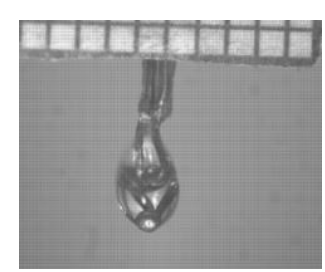

$0.4 \mathrm{~s}$

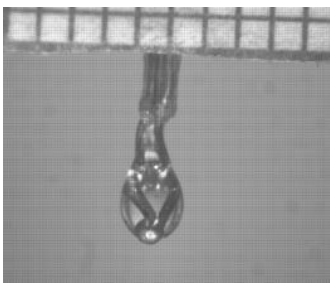

$4.78 \mathrm{~s}$

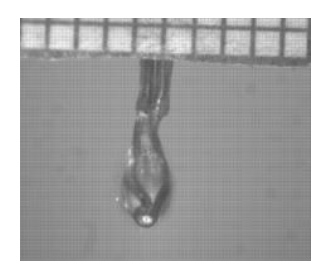

$0.42 \mathrm{~s}$

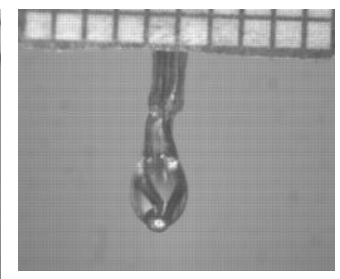

$10 \mathrm{~s}$

Figure 3: Droplet images at $50 \mathrm{fps}$ during the depressurized evaporation of a $75 \%$ ethanol $-25 \%$ water droplet. (The ambient pressure drops from 1 atmosphere to 2400Pa.)

\subsection{Numerical Results}

The calculation methods for evaporation rate of a multi-component droplet have been investigated by many researchers involving Equaiton (23) introduced by Sazhin et al. [18]. Also, Brenn et al. [30] and Ebrahimian et al. [31] suggested the following formula respectively:

$$
\begin{gathered}
\dot{m}=2 \pi \sum_{i=1}^{N} a_{V, i}\left(\bar{\rho} \overline{D_{i}}\right)_{g} S h_{i}^{*} \ln \left(1+B_{M, i}\right) \\
\dot{m}=\frac{2 \pi r_{d} \rho_{g}\left\{\left[\sum_{i=1}^{N} D_{i g}\left[1-X_{i}^{s}+Y_{i}^{s} \sum_{\substack{k=1 \\
k \neq i}}^{N} \frac{X_{k}^{s}}{Y_{k}^{s}}\right] S h_{i}\left(Y_{i}^{s}-Y_{i}^{\infty}\right)\right]-\left[\sum_{i=1}^{N} Y_{i}^{s} \sqcup \sum_{k=1}^{N} D_{k g}\left[1-X_{k}^{s}+Y_{k}^{s} \sum_{\substack{a=1 \\
a \neq k}}^{N} \frac{X_{a}^{s}}{Y_{a}^{s}}\right] S h_{k}\left(Y_{k}^{s}-Y_{k}^{\infty}\right)\right]\right\}}{1-\sum_{i=1}^{N} Y_{i}^{s}}
\end{gathered}
$$

Figure 4 compares the numerical droplet surface temperatures calcuated by the above models. The working conditions are the same as those in Figure 2. The numerical results calculated by Brenn model [30] agree well with those from Ebrahimian model [31], however predicting a higher droplet temperature than the experimental data. In contrast, the surface tempeatures calculated by the present model are more comparable to the measured data. Also, in Figure 4, the numerical droplet surface temperature is higher than the experimental data. This can be explained by the occurrence of bubble and bubble burst during the experiments, shown in Figure 3, accelerating the cooling rate of droplet. 


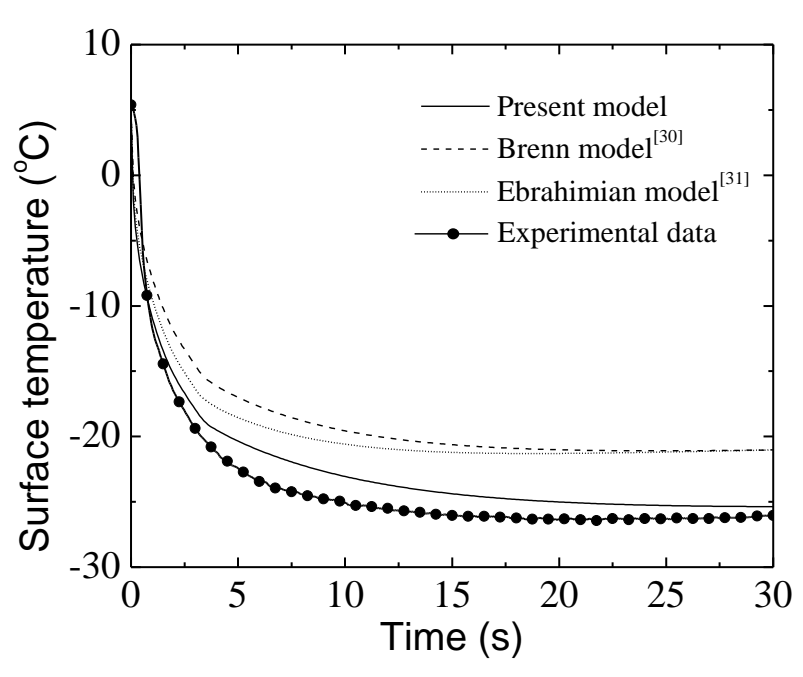

(a)

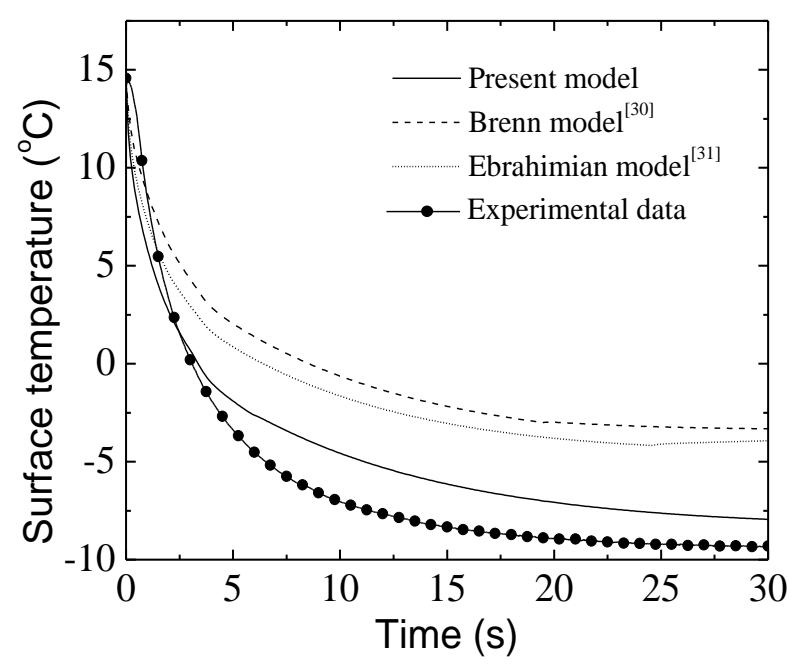

(b)

Figure 4: Comparisions of the numerical droplet surface temperatures with the measured droplet temperatures. (a: for a $75 \%$ ethanol $-25 \%$ water droplet, b: for a $50 \%$ acetic acid $-50 \%$ water droplet.)

Figure 5 shows the plots of the Spalding mass transfer number $B_{\mathrm{M}}$ versus time predicted by the present model for a $75 \%$ ethanol $-25 \%$ water mixture droplet under the same working condition in Figure 2(a). $B_{\mathrm{M}}$ signifies the difference of mass fraction of vapor between the droplet surface and in aimbent environment. $B_{\mathrm{M}}$ increases during the pressure dropping stage directly resulted from the decreasing ambient pressure according to Equations $(31,32)$. $B_{\mathrm{M}}$ decreases contiuously till the pressure reaches constant due to the decrease of droplet temperature.

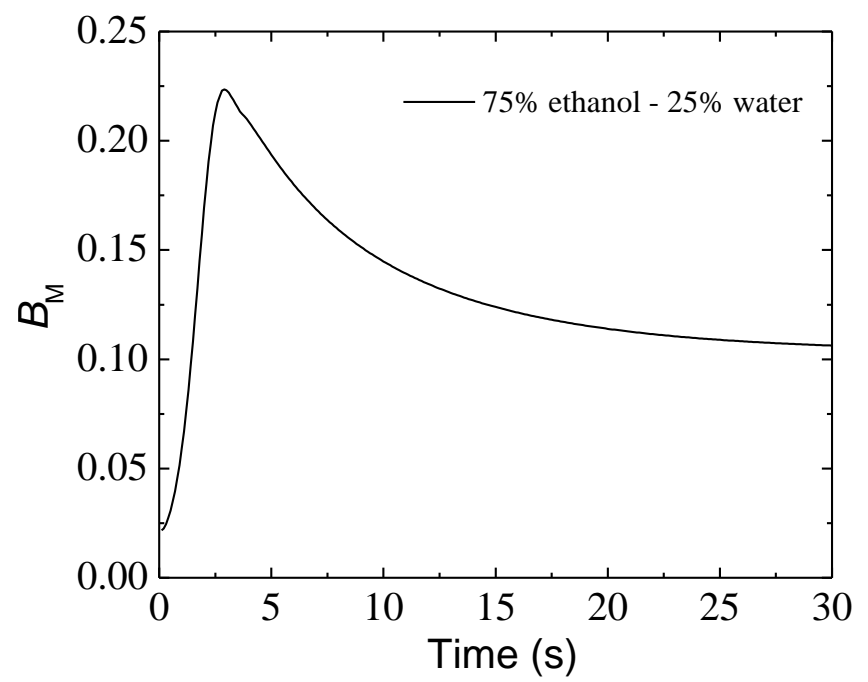

Figure 5: The plots of numerical Spalding mass transfer number $B_{\mathrm{M}}$ versus time.

Figure 6 shows the temporal variations of numerical $N u, S h$ and $R e$ for a $75 \%$ ethanol $-25 \%$ water droplet (the same initial and ambient conditions as those in Figure 2(a)). Reynolds number decreases quickly during the pressure dropping stage and reaches zero at $t=5 \mathrm{~s}$. Similarly, $N u$ 
number and Sh number declines during the first stage, illustrating strong convection, and maintain at 2 during the pressure constant stage.

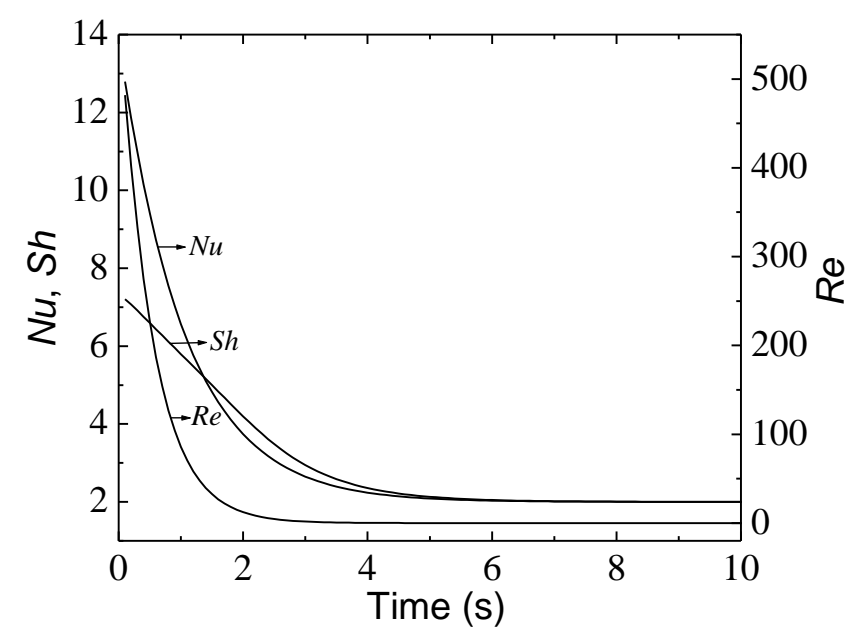

Figure 6: The variations of $N u, S h$, and $R e$ versus time for a $75 \%$ ethanol $-25 \%$ water droplet during depressurized evaporation.

\subsection{Concentration Distribution and Temperature Distribution within Droplet}

A coordinate transformation method is applied to solve moving boundary problem in the present model. Such moving boundary problem has been previously solved in the conventional model and moving boundary model reported by Gusev et al. [32]. In Reference [32], the droplet radius was assumed to be proportional to time step $t$. Figure 7 compares the numerical ethanol mass fraction $Y_{\text {eth }}$ versus $r / r_{\mathrm{s}}$ computed separately by the present model, the conventional model and the moving boundary model [32]. At $t>0.001 \mathrm{~s}$, the values of $Y_{\mathrm{eth}}$ calculated by the current model fall between the numerical results by the other two models.

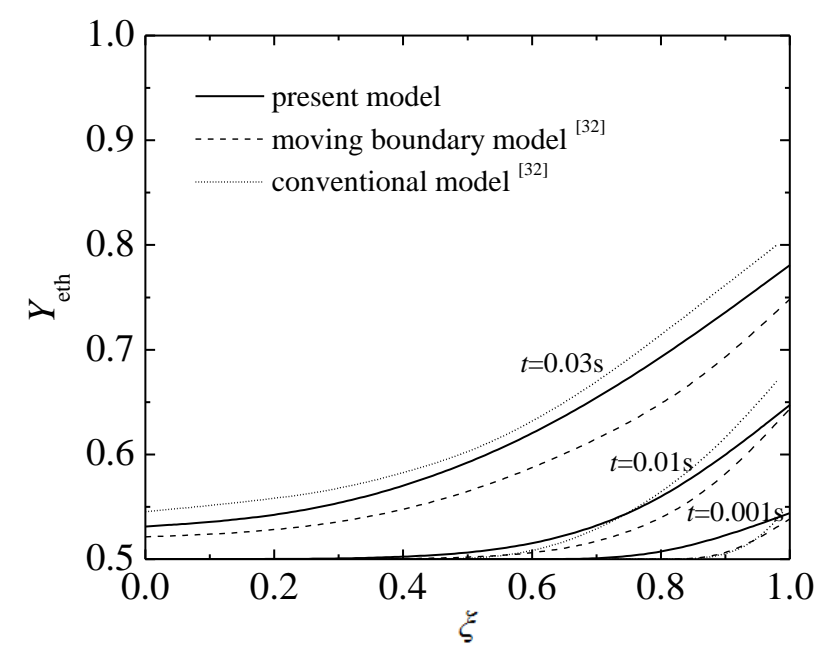

Figure 7: The plots of ethanol mass fraction $Y_{\text {eth }}$ versus $r / r_{\mathrm{s}}$ as predicted by the moving boundary model in reference [32] (dashed), the conventional model (dotted) and the present model (solid). (An initial 50\% ethanol $-50 \%$ acetone mixture droplet is used, with the initial diameter equals to $142.7 \mu \mathrm{m}$, the droplet velocity is $12.71 \mathrm{~m} / \mathrm{s}$, and the droplet temperature maintains at $37.5^{\circ} \mathrm{C}$.) 
Using the current model, Figures 8 and 9 show the concentration distribution and the temperature distribution within the ethanol/water droplet and the acetic acid/water droplet, separately, during depressurized evaporation. The results are obtained through numerical calculations at the same initial conditions of Figures 2(a) and 2(b), respectively.

Figures 8(a) and 9(a) indicate a significant concentration gradient within the bicomponent droplets during depressurized evaporation for ethanol/water and acetic acid/water droplets respectively. Figures 8 (b) and 9(b) illustrates the internal temperature distribution of the two droplets separately. The temperature gradient can not be ignored during the pressure dropping stage, shown in Figures. After $t=5 \mathrm{~s}$, the internal temperature within the liquid droplet, for both test cases, are almost uniform. This can be explained by two reasons: (1) the diffusion coefficient $D_{l}$ in liquid phase is of the order of $D_{l} \sim 10^{-9} \mathrm{~m}^{2} / \mathrm{s}$; and (2) the thermal diffusivity of solution is of the order of $\alpha$ $\sim 10^{-7} \mathrm{~m}^{2} / \mathrm{s}$. Therefore, the mass transfer rate is much slower than thermal diffusivity within the droplet.

Specifically, for an ethanol solution droplet, ethanol is more volatile than water, the mass concentration of ethanol within the liquid droplet gradually decreases during evaporation process, illustrated in Figure 8(a). In contrast, for an acetic acid solution droplet, water is more volatile, the mass concentration of acetic acid within the droplet is gradually increased as observed in Figure $9(a)$.

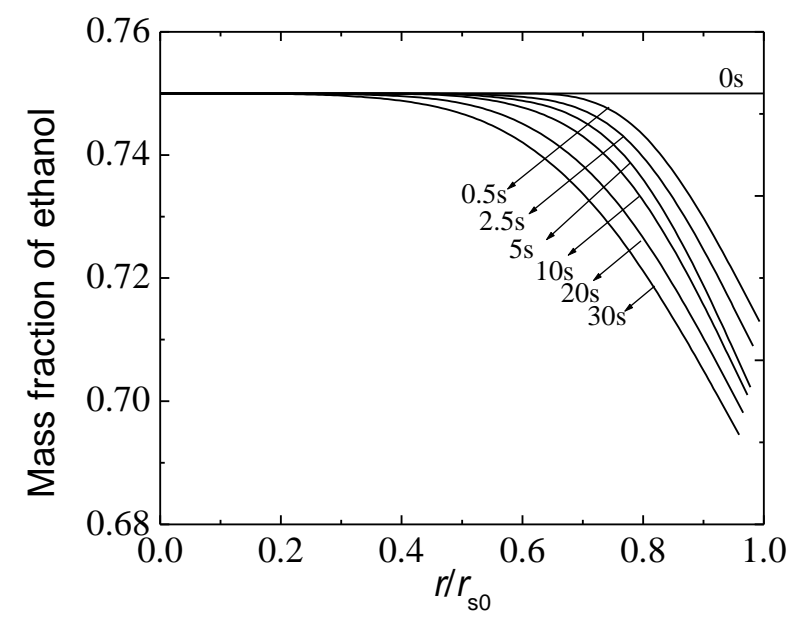

(a)

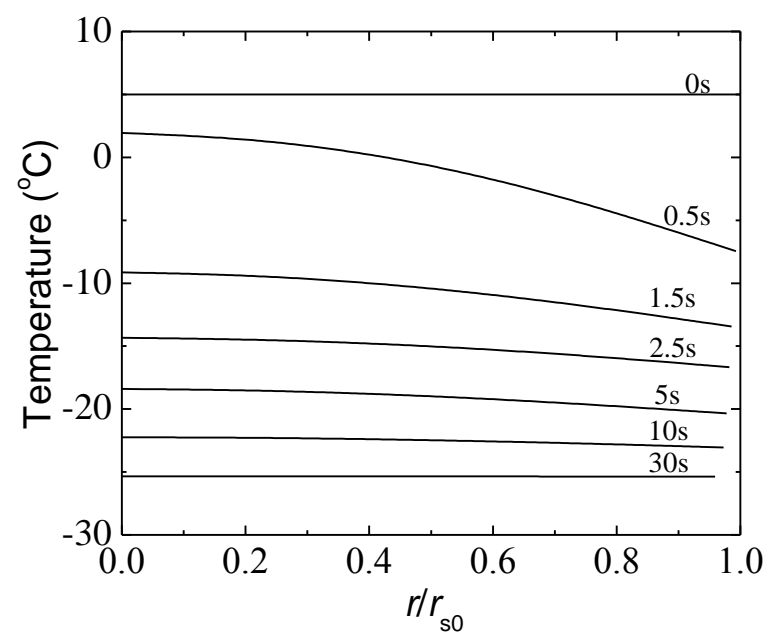

(b)

Figure 8: (a) The concentration distribution and (b) the temperature distribution within the $75 \%$ ethanol - $25 \%$ water mixture droplet. 


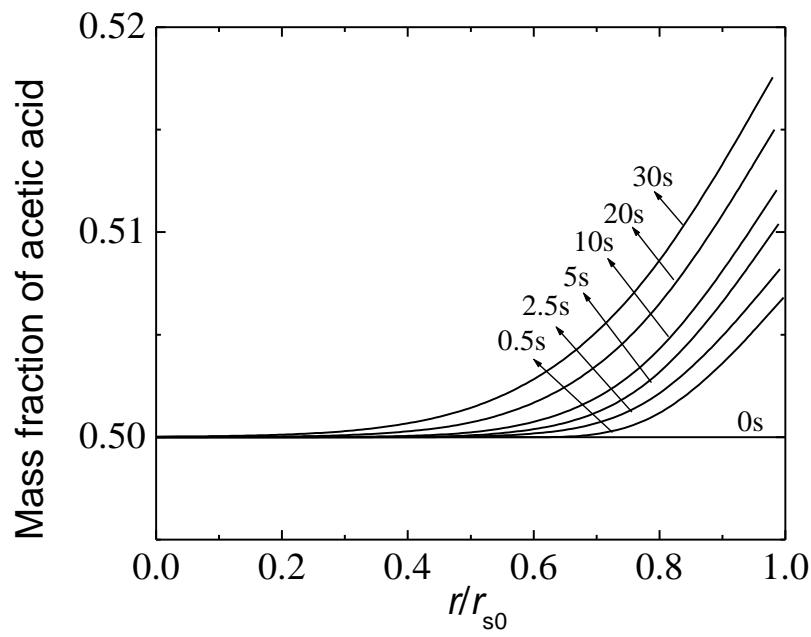

(a)

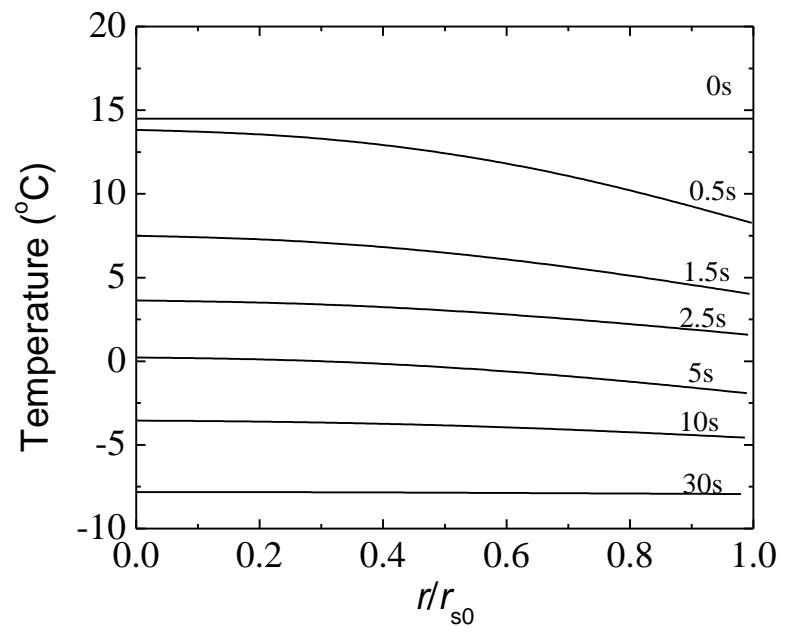

(b)

Figure 9: (a) The concentration distribution and (b) the temperature distribution within the 50\% acetic acid - $50 \%$ water mixture droplet.

During the model calculations, $\chi$ and $\chi_{\mathrm{D}}$ are introduced to consider the internal circulation flow enhancing heat and mass transfer inside the droplet. If $\chi_{\mathrm{D}}$ is assumed to be 1 , the concentration distribution within the $75 \%$ ethanol $-25 \%$ water mixture droplet is shown in Figure 10(a). Also, Figure 10(b) presents the numerical temperature distribution by assuming $\chi$ equals to 1 . Comparing Figure 10 with Figure 8, the concentration distribution and the temperature distribution within the droplet are more uniform by introducing $\chi_{\mathrm{D}}$ and $\chi$ during the pressure dropping stage. At $t=5 \mathrm{~s}$, the numerical mass fraction of ethanol at the droplet surface and the surface temperature are slightly higher than those assuming $\chi_{\mathrm{D}}=1, \chi=1$, respectively.

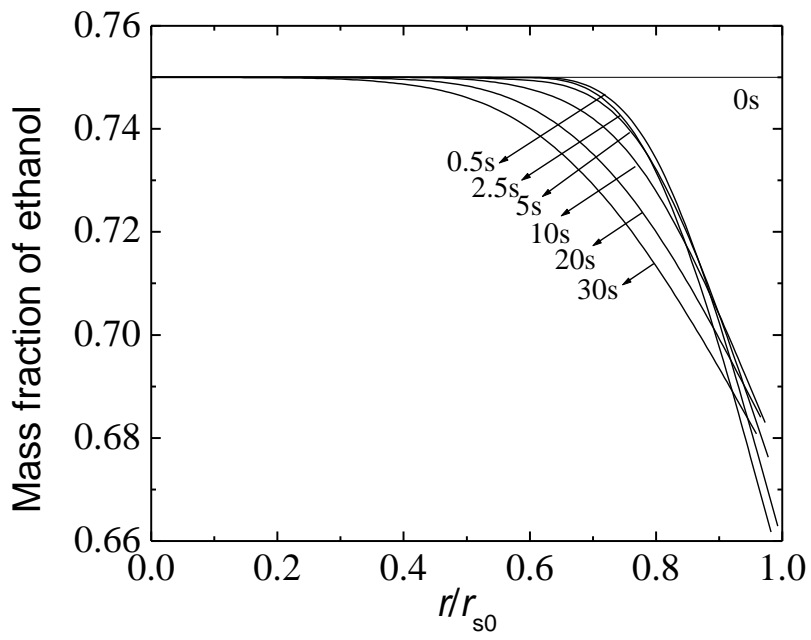

(a)

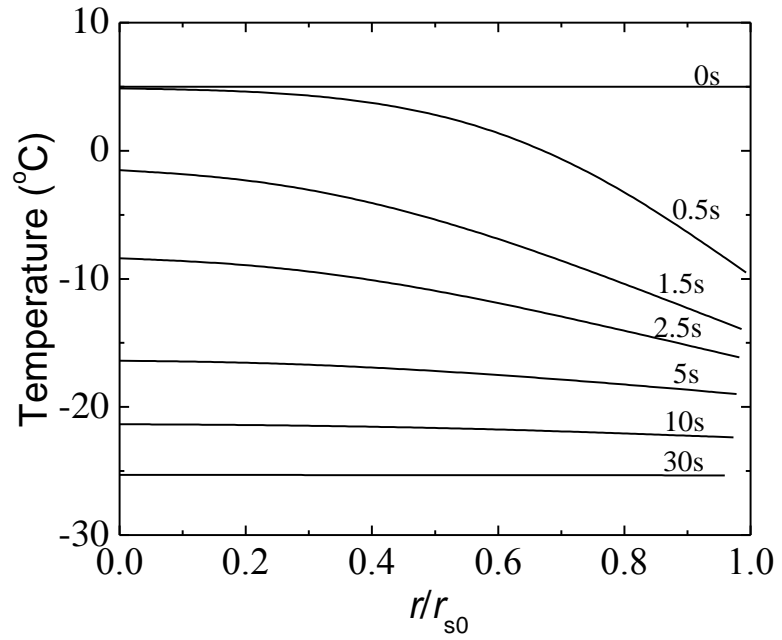

(b)

Figure 10: (a) The concentration distribution (assuming $\chi_{\mathrm{D}}=1$ ) and (b) the temperature distribution (assuming $\chi=1$ ) within the $75 \%$ ethanol - $25 \%$ water mixture droplet. 
In this paper, the activity coefficient $\gamma_{i}$ is introduced to take the vapor pressure at the droplet surface into consideration. Figure 11(a) shows the effect of $\gamma_{i}$ on the mass fraction of ethanol for a $75 \%$ ethanol - $25 \%$ water droplet. When considering the activity coefficient, the calculated evaporation rate for water is faster, resulting in a higher concentration of ethanol at the droplet surface. The reason is that $\gamma_{\text {water }}=1.57$, and $\gamma_{\text {ethanol }}=1.17$ for a $75 \%$ ethanol $-25 \%$ water droplet. While for Figure 11(b), the calculated evaporation rate for acetic acid is higher by introducing the activity coefficient, leading a lower concentration of acetic acid at the droplet surface. This can be attributed to $\gamma_{\text {water }}=1.04$, and $\gamma_{\text {acetic acid }}=1.2$ for a $50 \%$ acetic acid $-50 \%$ water droplet.

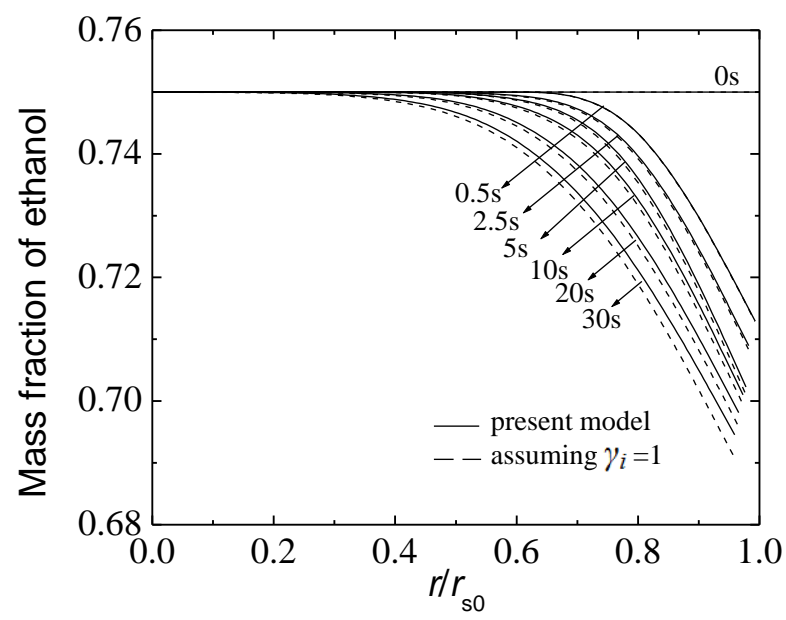

(a)

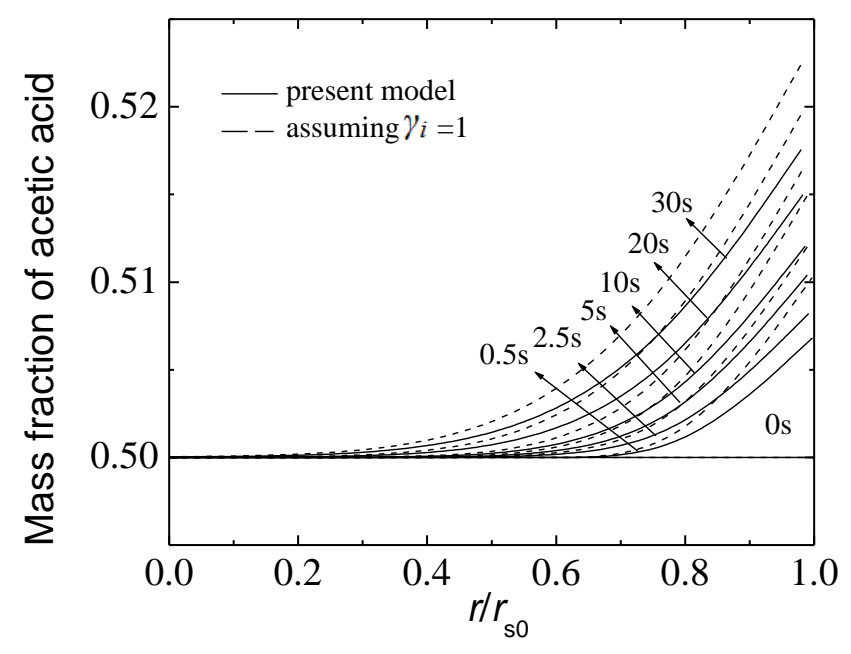

(b)

Figure 11: The effects of activity coefficient $\gamma_{i}$ on the (a) mass fraction of ethanol and (b) mass fraction of acetic acid within the droplet.

\subsection{The Effects on Droplet Evaporation Characterisitcs}

The main factors on droplet evaporation characteristics are numerically analyzed, including the effects of component, the final environmental pressure and the initial droplet diameter.

Figures 12 and 13 signify the effect of component on droplet surface temperature and dimensionless area change. In Figure 12(a), for ethanol/water droplets, droplet temperature decreases more rapidly as the ethanol concentration increases. This can be attributed to the lower boiling point of ethanol than water, and thus, higher vapor pressure at the ethanol droplet surface resulting in relatively higher volatility of ethanol and hence faster evaporation rate. Consequently, the droplet minimum temperature is lower for higher ethanol concentration with the shorter time needed to reach the minimum temperature. Figure 12(b) shows that till the droplet temperature maintains the low peak value, the dimensionless area has a linear relationship with time.

As for acetic acid/water droplets, in Figure 13(a), with a more acetic acid composition, the droplet temperature is higher during depressurized evaporation. Interestingly, as shown in Figure 13(b), the evaporation rate of a pure acetic acid droplet is the fastest. With the addition of water, the 
droplet evaporation rate slows down, revealing the presence of water within acetic acid/water droplet inhibits its evaporation. This result seemingly contradicts the fact that water has a lower boiling point than that of acetic acid, so the volatility of water is stronger than that of acetic acid (as seen in Figure 9(a)). The adverse effect can be explained by that the depressurized evaporation process is related with vapur pressure at the droplet surface. The vapor pressure is associated with composition and temperature. First, from the aspect of composition, the boiling point of acetic acid is the highest, the saturation vapor pressure at the pure acetic acid droplet surface is the lowest; and the boiling point of ethanol is the lowest, the saturation vapor pressure at the pure ethanol droplet surface is the highest. This indicates that the volatility of ethanol is the strongest, and that of acetic acid is the lowest at the same temperature. Second, the vapor pressure at the droplet surface is temperature dependent. With a higher temperature, the vapor pressure is greater. Due to the lowest latent heat of acetic acid, the droplet temperature is relatively higher during depressurized evaporation, resulting in a faster evaporation rate of a pure acetic acid droplet.

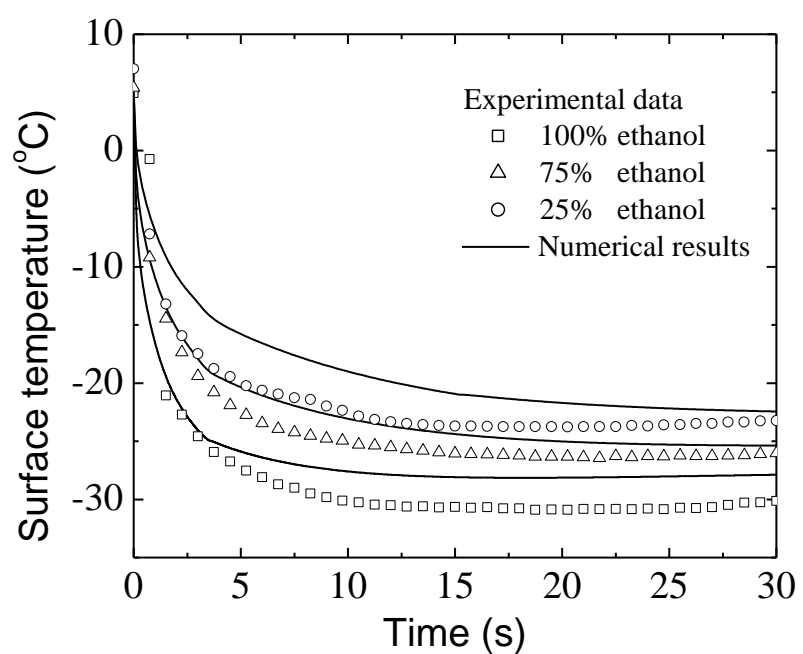

(a)

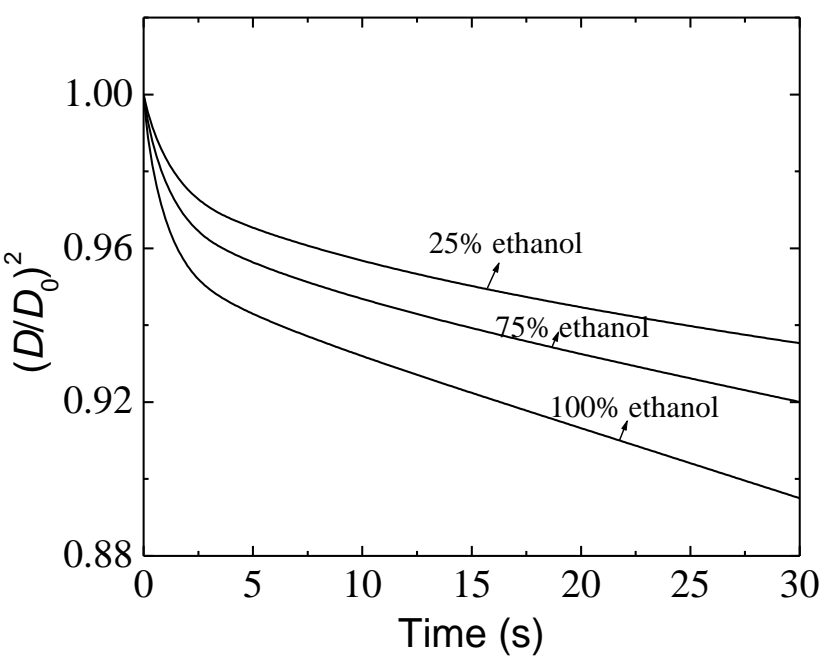

(b)

Figure 12: The effect of component on (a) droplet surface temperature change and (b) dimensionless area variation for an ethanol/water droplet. $\left(D_{0}=2 \mathrm{~mm}, T_{0}=5^{\circ} \mathrm{C}, T_{\mathrm{a}, 0}=15^{\circ} \mathrm{C}\right.$, and the ambient pressure in the test vessel dropping from 1 atm to $2400 \mathrm{~Pa}$.) 


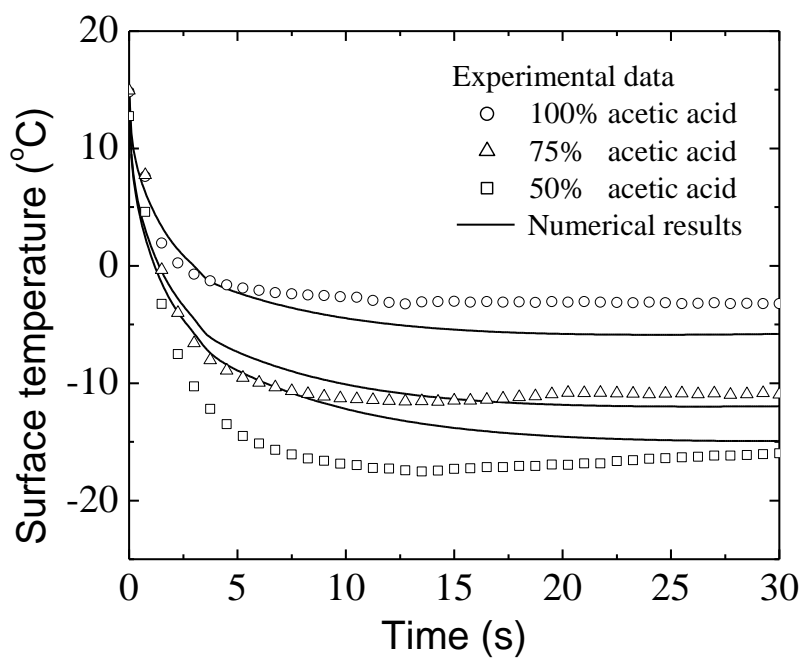

(a)

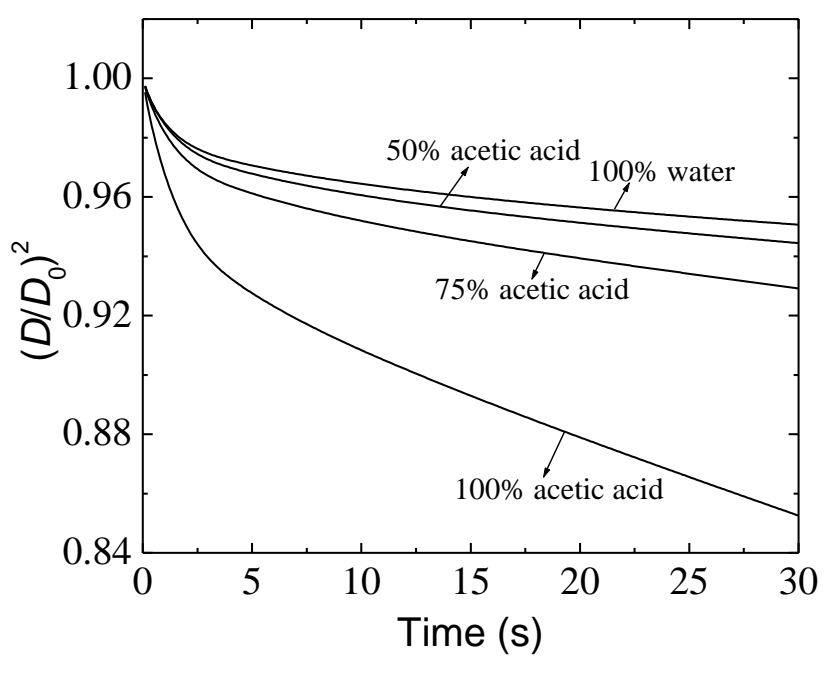

(b)

Figure 13: The effect of component on (a) droplet surface temperature change and (b) dimensionless area variation for an acetic acid/water droplet. $\left(D_{0}=2.2 \mathrm{~mm}, T_{0}=15^{\circ} \mathrm{C}, T_{\mathrm{a}, 0}=18^{\circ} \mathrm{C}\right.$, and the ambient pressure in the test vessel from 1 atmto 2000Pa.)

Figures 14 and 15 show the effect of final environmental pressure on droplet surface temperature change and dimensionless area variation. With a lower environmental pressure, the droplet evaporation rate is faster, the droplet minimum temperature is lower, but the time needed for droplet reaching the minimum temperature is almost the same. The reason is that under different experimental conditions, the time required for environmental pressure achieving the minimum value is almost identical. With a lower final environmental pressure, the air flow around the droplet moves faster bringing in the stronger convection effect and larger vapor diffusion coefficient, which accelerates the droplet evaporation rate during depressurized evaporation. Besides, the latent heat of vaporization is higher with a lower ambient pressure, thus the droplet temperature is also lower.

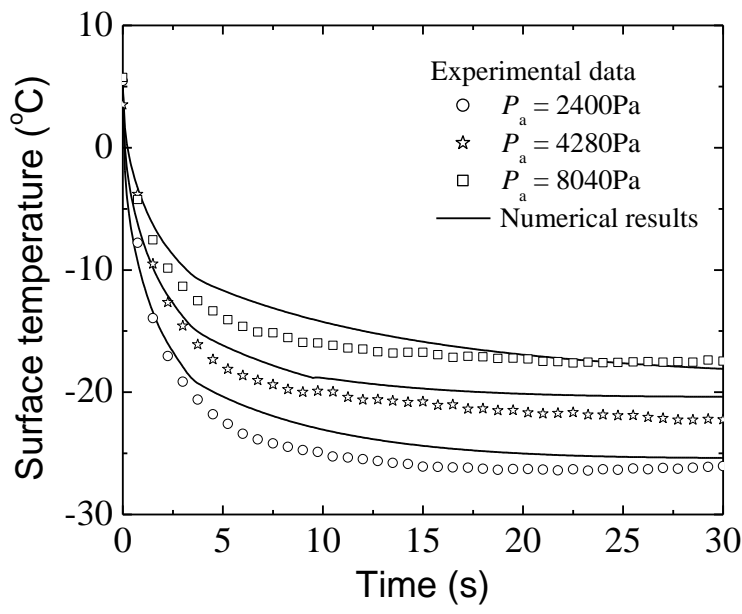

(a)

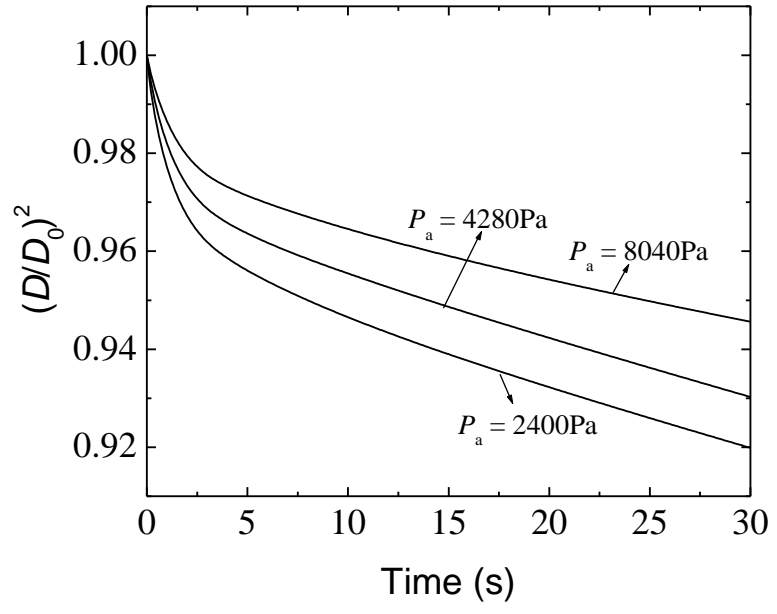

(b)

Figure 14: The effect of final environmental pressure on (a) droplet surface temperature and (b) dimensionless area variation for $75 \%$ ethanol - $25 \%$ water mixture droplets. $\left(D_{0}=2 \mathrm{~mm}, T_{0}=5^{\circ} \mathrm{C}\right.$, and $T_{\mathrm{a}, 0}=15^{\circ} \mathrm{C}$.) 


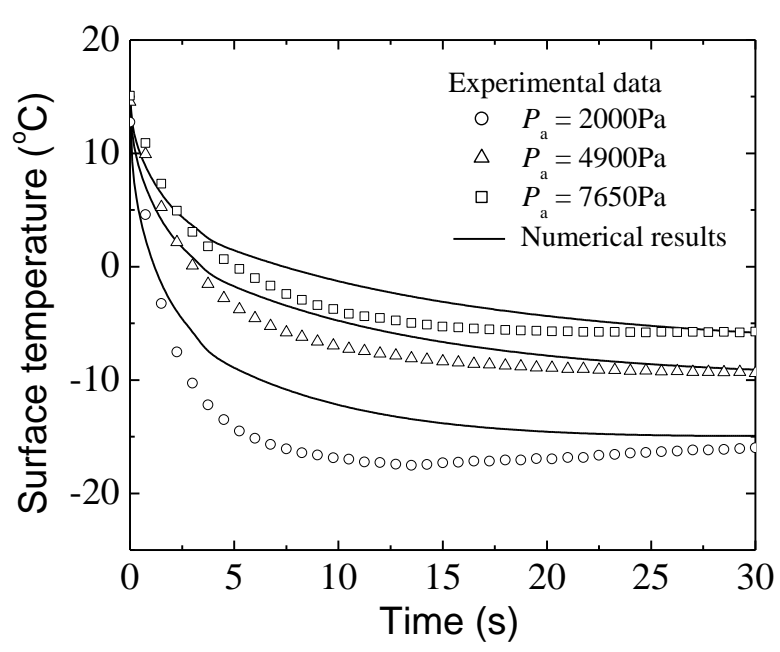

(a)

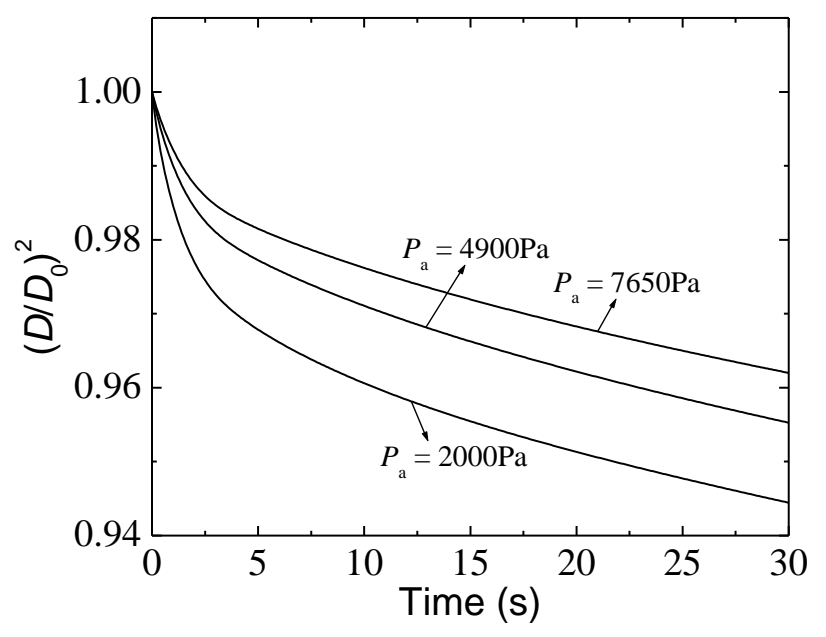

(b)

Figure 15: The effect of final environmental pressure on (a) droplet surface temperature change and (b) dimensionless area variation for $50 \%$ acetic acid - $50 \%$ water mixture droplets. $\left(D_{0}=2.2 \mathrm{~mm}, T_{0}\right.$ $=15^{\circ} \mathrm{C}$, and $T_{\mathrm{a}, 0}=18^{\circ} \mathrm{C}$.)

Figure 16 presents the effect of initial droplet diameter on numerical droplet surface temperature change and dimensionless area variation. With a smaller droplet diameter, the droplet evaporation rate is faster, and the droplet minimum temperature is lower during the pressure dropping stage. The droplet temperature increases gradually due to the convection between the droplet surface and the ambient air. In figure 16(b), for a $75 \%$ ethanol - $25 \%$ water mixture droplet with the initial diameter of $D_{0}=200 \mu \mathrm{m}$, when the ambient pressure in the test vessel drops from 1 atmosphere to $2400 \mathrm{~Pa}$, the total evaporation time is almost $12 \mathrm{~s}$.

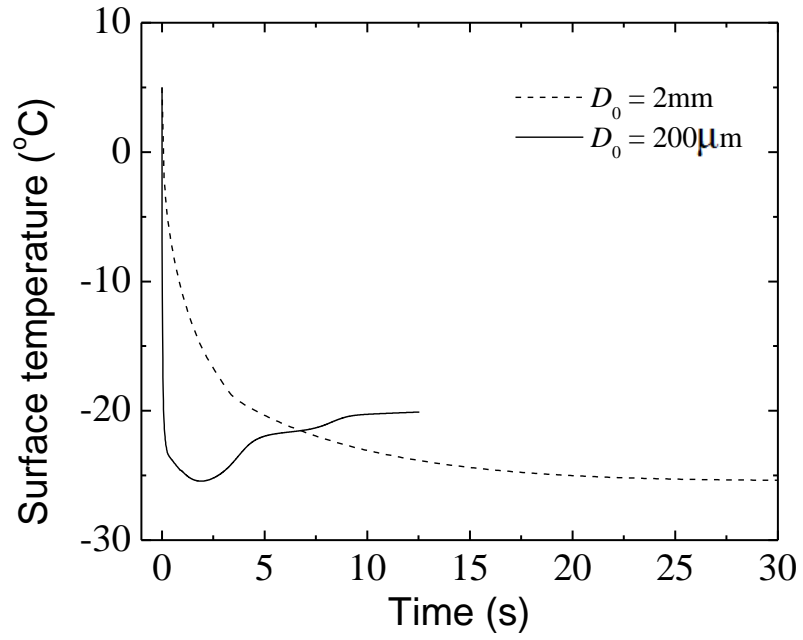

(a)

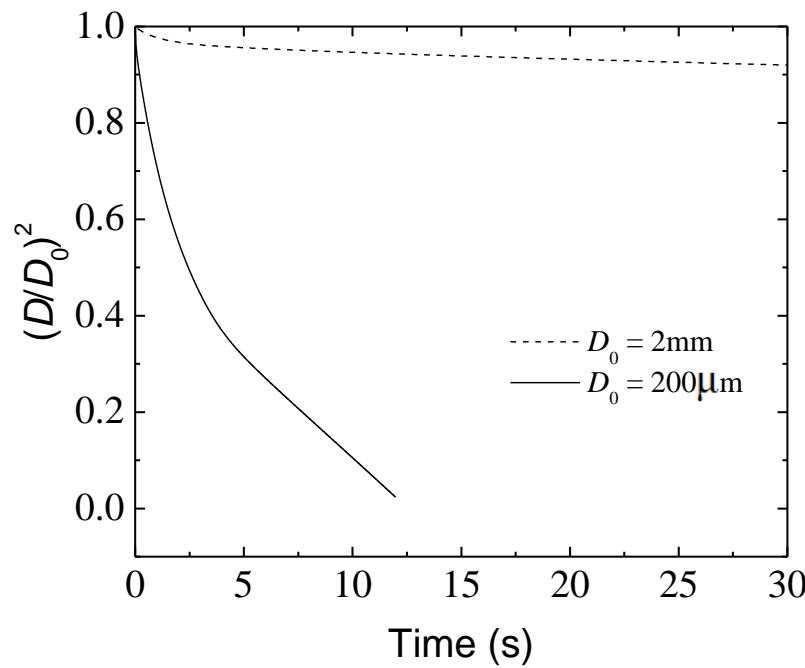

(b)

Figure 16: The effect of initial droplet diameter on (a) droplet surface temperature and (b) dimensionless area variation for $75 \%$ ethanol $-25 \%$ water mixture droplets. $\left(T_{0}=5^{\circ} \mathrm{C}, T_{\mathrm{a}, 0}=15^{\circ} \mathrm{C}\right.$, and the ambient pressure in the test vessel from 1 atm to $2400 \mathrm{~Pa}$..) 
An experimental and numerical analysis has been performed to investigate the evaporation process of a bicomponent (ethanol/water and acetic acid/water) droplet during depressurization. An experimental system was set up to measure the ambient pressure, ambient temperature and droplet temperature during depressurization. A numerical model has been developed to simulate the droplet evaporation process. The model considers the interior temperature distribution and concentration distribution inside the droplet, the heat transfers due to evaporation and convection at the droplet surface. Also, the activity coefficient was introduced to simulate the vapor partial pressure at the droplet surface. The model predictions agree well with the experimental measurements.

The temperature distribution and the concentration distribution inside the droplet are obtained based on numerical calculations. The results show both significant temperature gradient and concentration gradient inside the droplet during the fast pressure dropping stage. Thereafter, at the pressure maintenance stage, the temperature gradient within the droplet decreases gradually, but the concentration gradient is still not negligible. During depressurized evaporation, the mass fraction of ethanol within the ethanol/water droplet decreases gradually, while the mass fraction of acetic acid inside the acetic acid/water droplet is gradually increased.

The effects of component, final environmental pressure and initial droplet diameter on droplet evaporation are analyzed. The results reveal that with a higher ethanol concentration, the evaporation rate is faster, resulting in faster decrease in droplet temperature, lower droplet minimum temperature, and the shorter time needed to reach the minimum temperature. While as for acetic acid/water droplets, the evaporation rate of a pure acetic acid droplet is the fastest. With the addition of water, the droplet evaporation rate slows down, indicting that the presence of water within acetic acid/water droplet inhibits its evaporation. The reason is that the vapor pressure depends on both of composition and temperature. At the same temperature, the saturated vapor pressure of acetic acid is the lowest, compared to that of water and ethanol, resulting in the weakest volatility. On the other hand, the latent heat of acetic acid is the smallest, and hence the temperature is relatively higher for a pure acetic acid droplet during depressurization, which leads to a higher vapor pressure. The combined effect of the two aspects results in the complex evaporation characteristics for acetic acid/water droplets. The final environmental pressure also has significant impact on droplet evaporation. With a lower final environmental pressure, the droplet evaporations faster and reaches lower droplet minimum temperature, while requiring almost the same time to achieve the low temperature peak. With a smaller droplet diameter, the droplet evaporation rate is faster, and the droplet minimum temperature is lower during the pressure dropping stage. 


\section{Acknowledgements}

The research was supported by the National Science Foundation of China (NO. 51406055), and the Fundamental Research Funds for the Central Universities of Ministry of Education (China) (NO. 2014MS106 and NO. 2014ZD34).

\section{NOMENCLATURE}

$A_{\mathrm{C}} \quad$ cross section area in Eq. (45)

$B_{\mathrm{M}} \quad$ Spalding mass transfer number

$B_{\mathrm{T}} \quad$ Spalding heat transfer number

$C_{\mathrm{P}} \quad$ specific heat capacity $\left(\mathrm{J} \mathrm{Kg}^{-1} \mathrm{~K}^{-1}\right)$

$D$ diffusion coefficient $\left(\mathrm{m}^{2} \mathrm{~s}^{-1}\right)$

$L \quad$ latent heat of vaporization $\left(\mathrm{J} \mathrm{Kg}^{-1}\right)$

Le Lewis number

$M \quad$ molecular weight $\left(\mathrm{Kg} \mathrm{mol}^{-1}\right)$

$m \quad$ mass $(\mathrm{Kg})$

$\dot{m}$ mass vaporization rate $\left(\mathrm{Kg} \mathrm{s}^{-1}\right)$

$\mathrm{Nu}$ Nusselt number

$P \quad$ pressure $(\mathrm{Pa})$

$P e \quad$ Peclet number

Pr Prandtl number

$q \quad$ heat flux $\left(\mathrm{W} \mathrm{m}^{-2}\right)$

$R \quad$ gas constant $\left.\left(\mathrm{J} \mathrm{mol}^{-1} \mathrm{~K}^{-1}\right)\right)$

Re Reynolds number

radial distance $(\mathrm{m})$

Sc Schmidt number

Sh Sherwood number

$T$ temperature (K)

$t \quad$ time (s)

$u_{\mathrm{a}} \quad$ air velocity $\left(\mathrm{m} \mathrm{s}^{-1}\right)$

$u_{\mathrm{s}}$ maximal liquid velocity at droplet surface $\left(\mathrm{m} \mathrm{s}^{-1}\right)$

$V \quad$ volume of the test vessel

$X$ molar fraction

$Y \quad$ mass fraction

\section{Greek symbols}

$\alpha \quad$ the parameter in Eq. (35)

$\beta \quad$ the parameter in Eq. (35)

$\gamma \quad$ activity coefficient

$\varepsilon \quad$ the fraction of evaporation rate in Eq. (22); or characteristic Lennard-Jones energies

$\eta$ dimensionless factor in computational coordinate

$\lambda$ thermal conductivity $\left(\mathrm{W} \mathrm{m}^{-1} \mathrm{~K}^{-1}\right)$

$\mu \quad$ dynamic viscosity (Pa s)

$\rho$ density $\left(\mathrm{Kg} \mathrm{m}^{-3}\right)$

$\sigma \quad$ characteristic Lennard-Jones lengths

$\varphi \quad$ parameter defined by Eqs. (41) and (42)

$\chi \quad$ Effective coefficient

\section{Subscripts}

a ambient air

c droplet center

eff Effective

h Convection

$i \quad$ index for species

$l \quad$ Liquid

m Evaporation

r Reference

s droplet surface

$v \quad$ vapor phase

0 initial state

\section{Superscripts and overscore}

- $\quad$ average value

* modified value 


\section{REFERENCES}

[1] I. Owen and J.M. Jalil, Heterogeneous flashing in water drops, International Journal of Multiphase Flow, 1991, 17(5), 653-660.

[2] I. Satoh, K. Fushinobu, Y. Hashimoto, Freezing of a water droplet due to evaporation-heat transfer dominating the evaporation-freezing phenomena and the effect of boiling on freezing characteristics, International Journal of Refrigeration, 2002, 25(2), 226-234.

[3] W.M. Liu, Q.C.Bi, L. Liu, Y.Q. Ji, Study on the shape and temperature variations within droplet in low pressure environment, Journal of Engineering Thermophysics, 2007, 28(6), 957960 (in Chinese).

[4] W.F. Du, J.F. Zhao, K. Li, Experimental study on thermal-dynamical behaviors of liquid droplets during quick depressurization, Journal of Engineering Thermophysics, 2012, 33(8), 1349-1352 (in Chinese).

[5] H.T. Shin, Y.P. Lee, J. Jurng, Spherical-shaped ice particle production by spraying water in vacuum chamber, Applied Thermal Engineering, 2000, 20(5), 439-454.

[6] B.S. Kim, H.T. Shin, Y.P. Lee, J. Jurng, Study on ice slurry production by water spray, International Journal of Refrigeration, 2001, 24(2), 176-184.

[7] X.L. Zhang, W. Wang, Z.W. Li, X.F. Li, M. Yu, X.W. Liu, Modeling and experimental research of crystallization process of static droplet, Journal of Engineering Thermophysics, 2012, 33(8), 1419-1422 (in Chinese).

[8] W.L. Cheng, H. Chen, L. Hu, W.W. Zhang, Effect of droplet flash evaporation on vacuum flash evaporation cooling: Modeling, International Journal of Heat and Mass Transfer, International Journal of Heat and Mass Transfer, 2015, 84: 149-157.

[9] G. Aguilar, B. Majaron, W. Verkruysse, Y. Zhou, J.S. Nelson, E.J. Laverrnia, Theoretical and experimental analysis of droplet diameter, temperature, and evaporation rate evolution in cryogenic sprays, International Journal of Heat and Mass Transfer, 2001, 44(17): 3201-3211.

[10] Z.F. Zhou, W.T. Wu, B. Chen, G.X. Wang, L.J. Guo, An experimental study on the spray and thermal characteristics of R134a two-phase flashing spray, International Journal of Heat and Mass Transfer, 2012, 55(15-16): 4460-4468.

[11] Q. Luo, Q.C. Bi, Y.N. Han, Q.L. Zhang, Evaporation process of brine droplet at reducing pressure, CIESC Journal, 2013, 64(6), 2001-2006 (in Chinese).

[12] D. Zhang, D.T. Chong, J.J. Yan, Y.S. Zhang, Study on steam-carrying effect in static flash evaporation, International Journal of Heat and Mass Transfer, 2012, 55(17): 4487-4497. 
[13] D. Zhang, B.C. Zhao, J.J. Yan, Q.Z. Yang, Experimental study on static flash vaporization of aqueous $\mathrm{NaCl}$ solution at different flash speed: Steam-carrying effect, International Journal of Heat and Mass Transfer, 2014, 79: 618-627.

[14] A.E. Muthunayagam, K.R. Ramamurthi, J.R. Paden, Modelling and experiments on vaporization of saline water at low temperatures and reduced pressures, Applied Thermal Engineering, 2005, 25(5-6), 941-952.

[15] L. Liu, M. L. Mi, Theoretical investigation on rapid evaporation of a saline droplet during depressurization, Microgravity Science and Technology, 2014, 25, 295-302.

[16] S. Nešić, J. Vodnik, Kinetics of droplet evaporation, Chemical Engineering Science, 1991, 46(91): 527-537.

[17] S.R. Gopireddy, E. Gutheil, Numerical simulation of evaporation and drying of a bicomponent droplet, International Journal of Heat and Mass Transfer, 2013, 66(6): 404-411.

[18] S.S. Sazhin, A. Elwardany, P.A. Krutitskii, G. Castanet, F. Lemine, E.M. Sazhina, M.R. Heikal, A simplified model for bi-component droplet heating and evaporation, International Journal of Heat and Mass Transfer, 2010, 53(21-22), 4495-4505.

[19] S.S. Sazhin, A.E. Elwardany, P.A. Krutitskii, V. Deprédurand, G. Castanet, F. Lemoine, E.M. Sazhina, M.R. Heikal, Multi-component droplet heating and evaporation: Numerical simulation versus experimental data, International Journal of Thermal Science, 2011, 50(7): 1164-1180.

[20] C. Maqua, G. Castanet, F. Lemoine, Bicomponent droplets evaporation: Temperature measurements and modelling, Fuel, 2008, 87, 2932-2942.

[21] A. L. Yarin, G. Brenn, D. Rensink, Evaporation of acoustically levitated droplets of binary liquid mixtures, International Journal of Heat and Fluid Flow, 2002, 23, 471-486.

[22] S. Raghuram, V. Raghavan, D.N. Pope, G. Gogos, Numerical study of marangoni convection during transient evaporation of two-component droplet under forced convective environment, International Journal of Heat and Mass Transfer, 2012, 55(25-26): 7949-7957.

[23] V. Ebrahimian, C. Habchi. Towards a predictive evaporation model for multi-component hydrocarbon droplets at all pressure conditions, International Journal of Heat and Mass Transfer, 2011, 54(15-16): 3552-3565.

[24] B. E. Polling, J. M. Prausnitz, J. P. O'Connell, The Properties of Gases and Liquids, Fifth Edition, McGraw-Hill, New York, 2001.

[25] B. Abramzon, W. A. Sirignano, Droplet vaporization model for spray combustion calculations, International Journal of Heat and Mass Transfer, 1989, 32, 1605-1618. 
[26] R. S. Miller, K. Harstad, J. Bellan, Evaluation of equilibrium and non-equilibrium evaporation models for many-droplet gas-liquid flow simulation, International Journal of Multiphase Flow, 1998, 24(6), 1025-1055.

[27] R. S. Hansen, F. A. Miller, S. D. Christian, Activity coefficients of components in the systems water-acetic acid, water-propionic acid and water-n-butyric acid at $25^{\circ}$, The Journal of Physical Chemistry, 1955(5), 391-395.

[28] B. Abramzon, S. Sazhin. Convective vaporization of a fuel droplet with thermal radiation absorption. Fuel, 2006, 85(1): 32-46.

[29] G. L. Hubbard, V. E. Denny, A. F. Mills. Droplet evaporation: Effects of transient and variable properties. International Journal of Heat and Mass Transfer, 1975, 18(9): 1003-1008.

[30] G. Brenn, L. J. Deviprasath, F. Durst, C. Fink. Evaporation of acoustically levitated multicomponent liquid droplets. International Journal of Heat and Mass Transfer, 2007, 50(25-26): 5037-5086.

[31] V. Ebrahimian, C. Habchi. Towards a predictive evaporation model for multi-component hydrocarbon droplets at all pressure conditions. International Journal of Heat and Mass Transfer, 2011, 54(15-16): 3552-3565.

[32] I. G. Gusev, P. A. Krutitskii, S. S. Sazhin, A. E. Elwardany. New solutions to the species diffusion equation inside droplets in the presence of the moving boundary. International Journal of Heat and Mass Transfer, 2012, 55: 2014-2021. 